Sheffield

Hallam

University
Centre for

Regional Economic

and Social Research

\title{
An Evaluation of the Impact of Weston Park Cancer Support Centre
}

January 2020

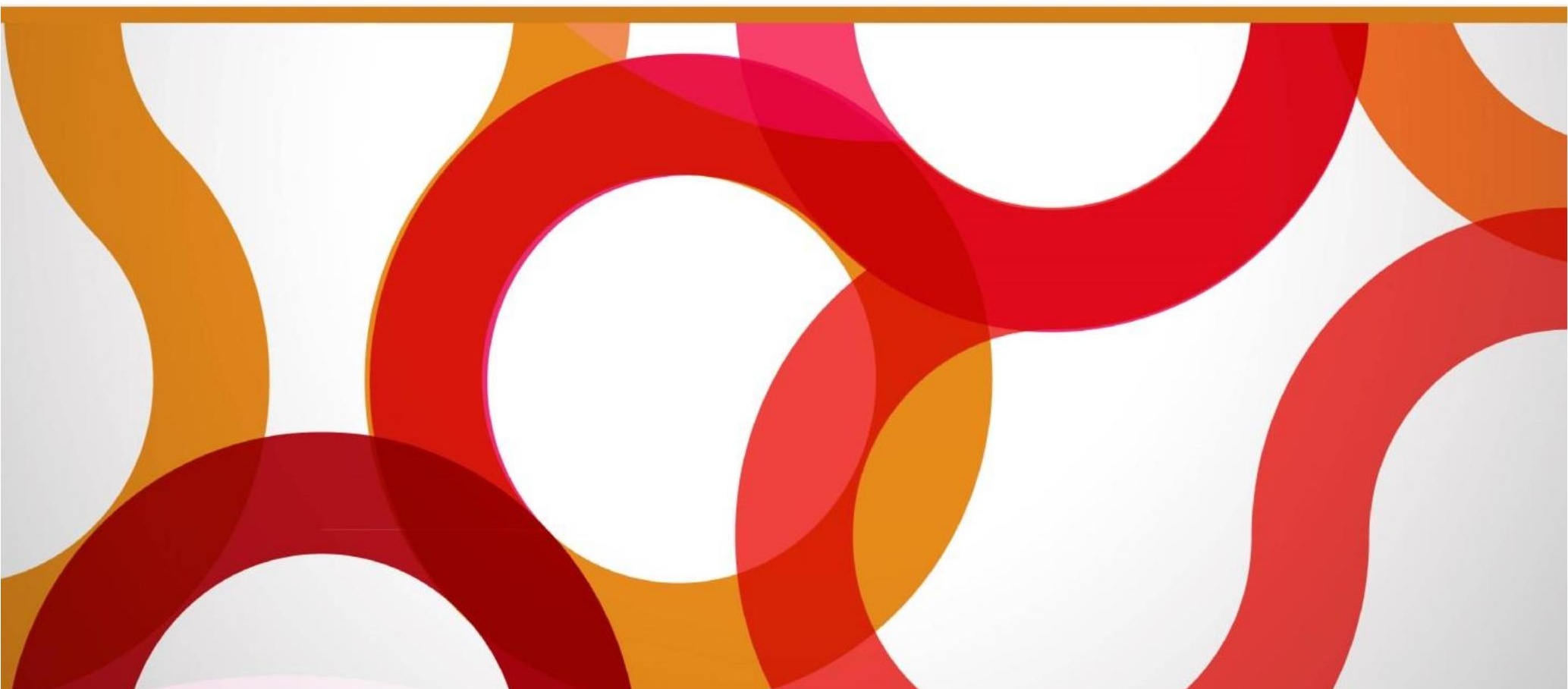




\section{An Evaluation of the Impact of Weston Park Cancer Support Centre}

Author(s):

Chris Dayson

Jan Gilbertson

David Leather

January 2020

DOI: 10.7190/cresr.2019.3247799239 


\section{Acknowledgements}

The authors are grateful to all the staff at the Weston Park Cancer Support Centre who supported the evaluation. We would like to thank Sarah Saunby who advised on available CSC data and helped us with our data scoping and assessment. Special thanks also go to Isabel Hartland for her help with data sharing and contract agreements and to Hannah Hall and Emma Clarke for skilfully taking up liaison for the project part way through the evaluation. 


\section{Contents}

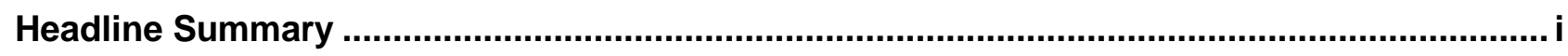

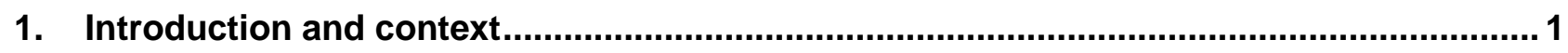

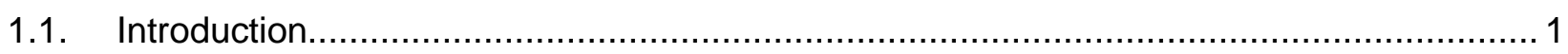

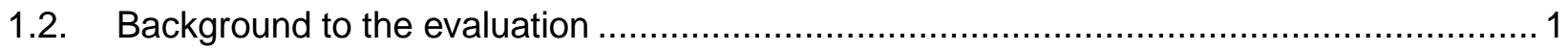

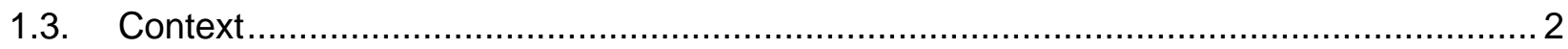

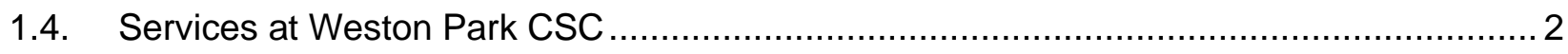

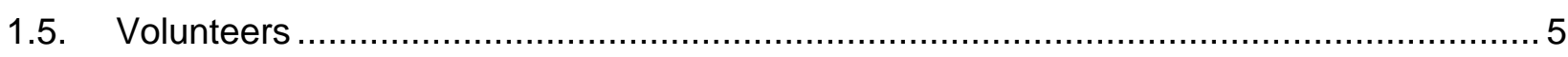

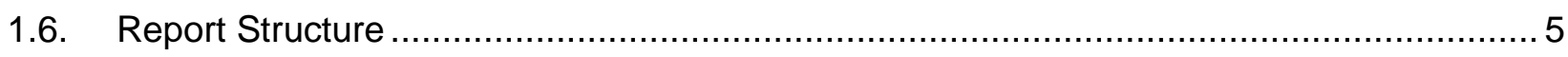

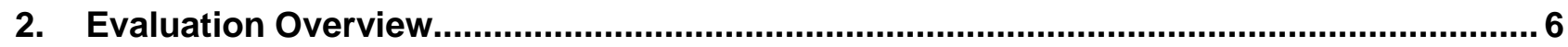

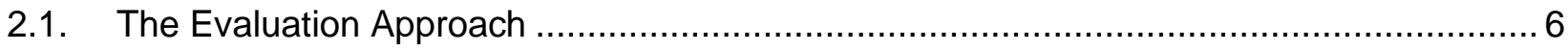

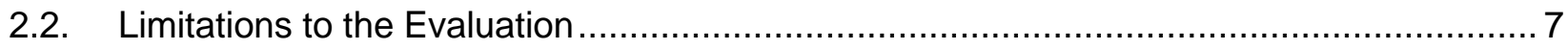

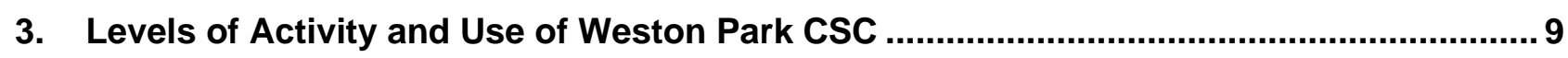

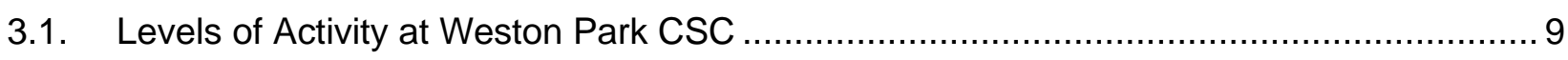

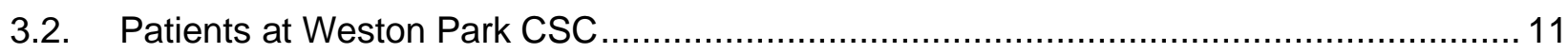

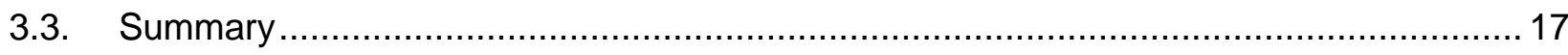

4. The Quality and Impact of Weston Park CSC Services and Courses ............................ 18

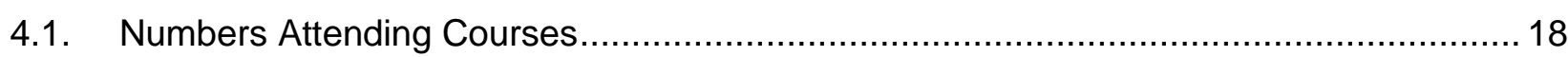

4.2. Quality and satisfaction with services and courses ................................................ 18

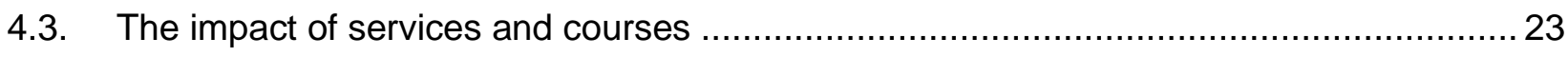

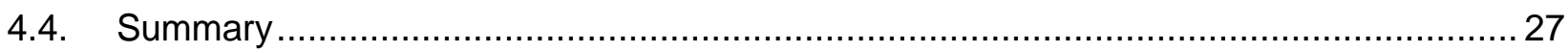

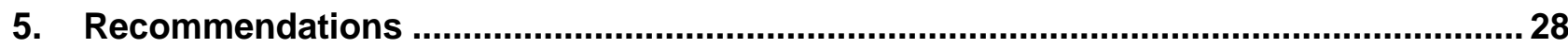

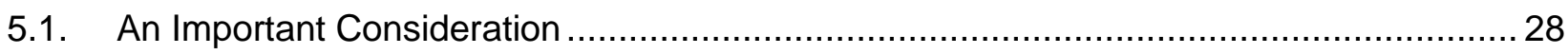

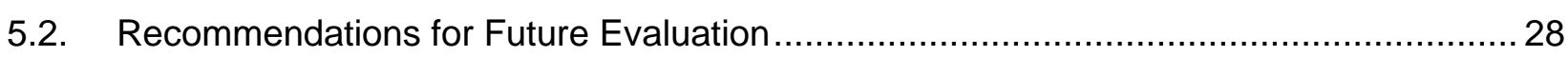

Appendix 1: Methodology and Glossary of Terms ............................................................. 


\section{Headline Summary}

\section{Levels of Activity and Use of the Cancer Support Centre}

- In total there were 60,065 recorded contacts with the CSC between January 2014 and March 2019.

- Between 2014 and 2018 the number of enquiries and contacts at the Centre increased by $40 \%$ from 9,500 to 13,300 .

- The CSC mainly serves Sheffield and the South Yorkshire region but receives enquiries from other parts of the UK too.

- It is apparent that there are wards in Sheffield where people experience a high frequency of cancer but low use of the Centre. These include some of the most deprived wards such as Firth Park, Southey, Burngreave, Darnall, Arbourthorne and parts of Gleadless Valley.

- When compared with new cases of cancer, men and those aged over 60 are underrepresented at the CSC and there are a higher proportion of people in the 40-59 age groups.

- Though the cancer patients using the Centre are typical of most people living with cancer in the UK, there are people experiencing certain types of cancer underrepresented at the Centre. It is likely that the needs of BAME populations are not being adequately met.

- Almost half of the patients contacting the Centre were enquiring about welfare benefits.

\section{Quality and Impact}

- Almost all the people utilising the various services at the CSC reported high levels of satisfaction with the service they received.

- The Centre provides a warm welcoming service that helps to put people at ease and makes them feel safe and secure at a time of uncertainty. Staff members and volunteers are very helpful and friendly.

- People contacting the Centre through telephone enquiries and using the Drop-in service found that these services were very informative, and they received the relevant information they needed.

- Feedback on all the various courses offered at the Centre was extremely positive.

- Contact with the Centre and usage of services and courses resulted in people feeling more supported and less isolated and alone.

- A major impact of the services and courses delivered by the CSC was associated with the social value of meeting people and having contact with others who were in a similar situation.

- After attending services and courses the majority of people reported having less stress and anxiety and were feeling much calmer and happier as a result. Practices such as Mindfulness and Acupuncture helped people to relax and improved their ability to cope with illness and other related issues. 
- Income gained for clients who received Welfare Advice support and were followed up by Citizens Advice, responsible for delivering the service for the CSC, amounted to $£ 1,608,004$ for 288 clients in 2016-2017 and $£ 1,375,298$ for 233 clients in 2017-18. These figures underestimate the total financial value gained, as only a proportion of clients are typically followed up.

- The CSC also benefits from essential volunteer support and volunteers provide information and support at local hospitals to cancer patients. Volunteers contribute greatly to the Centre's friendly, welcoming atmosphere and helpful service. Volunteers contributed five full time equivalent posts to the Centre and an annual economic value of over $£ 100,000$ in both 2018 and 2019.

- There may well be other social benefits emanating from the support provided by the CSC not currently recognised or measured by the Centre or included in this evaluation. These benefits accrue to beneficiaries of the CSC but also to their friends, families and carers and to wider society.

\section{Recommendations}

The findings outlined in this report point to recommendations that Weston Park CSC may wish to consider in the future.

Taking into account cancer prevalence rates, evidence of certain groups (men, the over 60 s and BAME populations) and types of cancer being underrepresented at the Centre, and that some deprived parts of Sheffield are experiencing levels of need not currently being met by the Centre, it is recommended that further investigation is undertaken to determine the reasons why these groups and communities have a lower support up-take at the CSC. The CSC will need to examine and develop new ways of reaching out to these areas and groups in the future.

- Recommendations for future evaluation include improvements to the Centre's main database and adopting more consistent data entry practices:

- Weston Park CSC has already made improvements to its main database and adopted an individual unique identifier across all services and courses. This means it will be possible to track an individual's use of services more accurately, for example, to see what support an individual is accessing and how many times different services are used.

- $\quad$ Regarding impact measurement the Centre should consider the following:

- $\quad$ Adopting standardised outcome measures for general health and subjective wellbeing as part of assessment.

- Using a standard set of questions in Course evaluations - there is potential for all course evaluations to include a set of generic questions which would make comparative analysis of course information easier.

- Routinely collecting NHS numbers would enable the CSC to link with other health databases and follow use of health and social services elsewhere.

- Valuing volunteer time - Volunteers are integral to the Centre and the support offered to cancer patients. The Centre therefore may find it helpful to utilise the data it collects to monitor the hours volunteers contribute with a view to placing a financial value on these inputs.

- Gathering in-depth qualitative information and ensuring better follow up of some welfare advice clients. Gathering more in-depth qualitative data would help to articulate a range of benefits and impacts of the various services offered by CSC which are not currently being captured effectively. Such data could provide the human-interest stories which could help showcase the work of the CSC. More detailed follow up on how welfare advice clients have used the extra income gained and what difference this has made would help the CSC assess more fully the impact of this service on people's lives. 


\section{Introduction and context}

\subsection{Introduction}

This report presents the findings from an evaluation of Weston Park Cancer Support Centre commissioned by Weston Park Cancer Charity. The evaluation was carried out between January and June 2019 by the Centre for Regional Economic and Social Research (CRESR) at Sheffield Hallam University.

\subsection{Background to the evaluation}

Weston Park Cancer Charity's vision is to create a better life for those people affected by cancer in the region. It raises over £2million a year to invest in high quality cancer research and local initiatives which help patients receive the best care possible in hospital or whilst living independently. Although by 2020 one in every two people is anticipated to develop cancer in their lifetime, cancer survival rates are improving. More people are living with the effects of cancer and its treatment. Weston Park Cancer Charity focuses on supporting these people and their families.

In May 2018, Weston Park Cancer Charity merged with Weston Park Cancer Support Centre (CSC). A new strategy is being launched which will set out the ambition for the new organisation over the coming years.

The strategy will set out much needed improvements to the ways that the impact of charitable investments in different projects is measured and evaluated. By way of a first step this evaluation of the impact of the CSC was commissioned. The evaluation has a few main purposes including to:

- $\quad$ Support the launch of the new strategy with a focus on 'showcasing' the work of the CSC; what's been achieved in the past and what it is hoped to achieve in the future.

- Show the primary audience for fundraising (the general public and existing supporters) the sorts of activities that their donations have funded over the years.

- 'Showcase' with health professionals and clients the quality and impact of CSC's work to encourage partnership working and (self) - referrals. 


\subsection{Context}

The NHS Long Term Plan (2019) ${ }^{1}$ sets out a vision for what cancer patients should expect from the health service. The plan emphasises early diagnosis and significantly improving cancer survival. Of relevance is the plan's commitment to ensuring that where appropriate everyone diagnosed with cancer will have access to personalised care. This includes needs assessment, a care plan and, health and wellbeing information and support delivered in line with the NHS Comprehensive Model for Personalised Care.

Sheffield itself is part of the South Yorkshire and Bassetlaw Cancer Alliance Programme, coterminous with the Integrated Care System (ICS) area, which brings together key organisations in local areas to coordinate cancer care and to improve outcomes for patients locally. Priorities include providing access to personalised support and implementing supported self-management follow-up pathways for patients. Weston Park CSC is a voluntary sector partner, helping to deliver personalised care. Sitting under the wider Cancer Alliance Programme the regional Macmillan funded Living With And Beyond Cancer Programme also aims to support people living with and beyond cancer and is specifically focussed on breast, bowel and prostate cancer. This Programme involves agreeing care and support that works for the individual and those close to them and also implementing new pathways after treatment that better identify individual's needs and post treatment issues to offer much more tailored and holistic support.

\subsection{Services at Weston Park CSC}

The CSC provides resources and information for people and offers a wide range of services and courses to patients, carers and families. Hospital staff and health care professionals also use the CSC as a resource of information.

Since opening in May 2005, the services offered by Weston Park CSC have grown and been shaped by listening to people who use and want to use the Centre. The Centre has employed focus groups to help develop the services and courses offered. Course evaluations are used to continually review courses and inform any changes and improvements made.

Weston Park CSC is unique in Sheffield and is a leading resource in the region. It brings together under one roof a significant range of services which aim to support the physical, emotional, practical, financial and spiritual aspects of living with and beyond a cancer diagnosis and treatment. The service is open to anyone affected by cancer and has no time-limit or restriction on its support, being wholly responsive to what matters most to each person at a point in time. The CSC prides itself on its warm and welcoming atmosphere and its relationship-based approach to the care and support it provides, often supporting people over multiple months and years. The CSC is driven by team work, it is a place where a multi-disciplinary team of nurses, radiographers, welfare advisors, complementary therapists, legal advisors, mental health practitioners, lifestyle coaches, support workers, volunteers and people with lived experience of cancer, work together to make holistic support a reality.

A brief outline of the main services offered by the Centre is detailed below. 


\section{Drop-in and Telephone Support Service}

The main service that Weston Park CSC offers is a Drop-in service. This service is distinctive as no appointment is needed to see staff some of whom are healthcare professionals. Anyone affected by cancer can drop-in for information, psychological support and advice from health care professionals experienced in oncology and palliative care. The CSC works closely with the medical teams; can act as advocates for people and make referrals and signpost people to relevant other services where necessary. The drop-in information and telephone helpline are open Monday to Friday 9 am $-5 \mathrm{pm}$. This is a very busy service and no appointment is required.

Courses are also delivered by the CSC to support patients and carers and to help them self-manage. All courses are facilitated by nurses at the Centre.

\section{‘Positive about life' (PAL)}

PAL is a 6-week course, designed for patients with any cancer. It covers topics such as stress and anxiety; why does the body react in different ways to stress and anxiety and how to manage those reactions including coping strategies. Coping with fatigue, how to encourage sleep and relaxation, healthy eating, and the benefits of activity and exercise. Also includes talking to friends and family (including children), getting the best from consultations, as well as living life to the full, and travel after cancer.

\section{Prostate 'Positive about life'}

This is a 3-week course which covers the PAL course outlined above but also understanding PSA levels, coping with the side effects of hormone therapy and dealing with relationship changes. Within this confidential and supportive environment, sensitive issues such as incontinence, changes in emotional responses and erectile dysfunction can be discussed by men all facing similar issues.

\section{Carers Course}

This five-week course supported anyone looking after someone with a cancer diagnosis. The course encouraged carers to look after themselves as well as the patients they are caring for, so the course covered similar topics as PAL including understanding stress and anxiety, coping strategies and healthy eating. The Carers course has since evolved into Carer's support available for any family member or friend caring for a cancer patient which can provide one-to-one support and advice at the centre with a healthcare professional or offer regular telephone support sessions.

\section{Bereavement course}

The Bereavement course is for people who have lost someone to cancer. It covers learning about the grieving process and exploring feelings so that those attending know that what they are feeling is normal under these sad and painful circumstances. The course also motivates attendees to look after themselves and discuss how they can rebuild their lives again. This is a 6-week programme of support. One-to-one support for bereaved people is offered by the CSC too.

Other services offered at the CSC are listed below.

\section{Auricular Acupuncture}

This service delivered in same sex groups is offered to help with hot flushes in prostate, breast and Gynae cancer patients. There are 8 hours of acupuncture per week, which can treat 48 people. 


\section{Mindfulness}

This service was offered on a one to one basis by a nurse in the CSC and has been developed into a group mindfulness session. Four sessions can be offered. This service can be very useful for people who are particularly struggling with focussing when under a lot of stress.

\section{Look Good Feel Better for women}

This service is a free of charge 'one off' skincare and make-up workshop for women with cancer run at the Centre by the charity 'Look Good Feel Better. The workshops offer hints and tips on how best to apply each product with particular care taken with key 'problem' areas resulting from cancer treatment, such as re-defining the eye area when ladies have lost brows and lashes. A full programme is run 3 times a month and can see 36 women in total. The free gift bag they receive to take away is full of cosmetics and worth approximately £200. Beauticians attend and show women how to use the products in the bag with many beauty tips for dry/sensitive skin.

\section{Look Good Feel Better for men}

These group sessions offer advice on skincare, shaving, grooming and problems that men may be facing as a result of cancer treatment. Run by volunteer skincare experts and local barbers it's an opportunity to ask questions and meet others in a similar situation. Free gift bag with skin care and sun protection products.

\section{Welfare Advice via Sheffield Citizens Advice}

This is a holistic service available for any Weston Park CSC users regardless of where they live. Thirty appointments are offered across the week, with three appointments at the Haematology day case unit one morning per week at the Royal Hallamshire Hospital. Trained and experienced advisers are skilled with working with people affected by cancer and can sensitively undertake a full benefits check, also looking at housing, employment, immigration and debt issues to maximise income.

\section{Free Legal Advice}

Six appointments every week are offered by solicitors to see people to discuss making a Will, Lasting Power of Attorney.

\section{Complementary Therapies}

These provide relaxing individual appointments for patients and their carers' in the CSC, supporting people coping with treatments for cancer and includes massage, shiatsu, reflexology, reiki, and relaxation techniques. There are 27 appointments available per week.

\section{Crafts}

Social therapy is offered for patients and carers to attend weekly afternoon session. This service can improve confidence and self-esteem and involves meeting others in similar situations. People can also talk to a health care professional if they have any issues they want to discuss. 


\section{Coffee Morning}

The Coffee Morning is held once a month. It provides an opportunity to meet others in similar situations and is for patients and families. The coffee morning can be used as a 'gentle' introduction to the CSC for some who find it difficult entering the Centre for support.

\subsection{Volunteers}

Currently, fourteen Support Centre volunteers provide the extra support and friendliness for people visiting the Centre (welcoming everyone, making drinks, keeping the kitchen tidy etc.) as well as supporting staff with administrative tasks such as topping up leaflets, packs, photocopying, and setting up workshops etc.

Volunteers have also been recruited and trained to attend the clinic at Weston Park Cancer Centre, to inform and describe to people affected by cancer the different support services provided in Sheffield and how they can access these. At Weston Park Hospital, volunteers obtain feedback from patients and families on the experience of using the hospital to support changes and improvements. There are presently two outpatient volunteers.

\subsection{Report Structure}

The rest of the report is structured as follows:

- $\quad$ Chapter 2: Evaluation Overview;

- Chapter 3: Levels of Activity and Use of Weston Park CSC;

- Chapter 4: The Quality and Impact of Weston Park CSC service and courses;

- Chapter 5: Recommendations;

- Appendix 1: Methodology and Glossary of Terms. 


\section{Evaluation Overview}

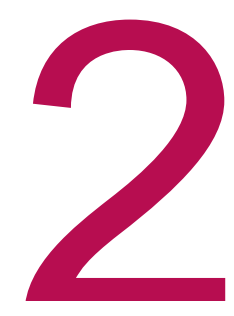

\subsection{The Evaluation Approach}

The evaluation aims to gain a better understanding of the CSC's impact in relation to a number of key areas. These include:

- The numbers of people helped, the way help was accessed, the type of help received, and the service used.

- The quantitative and qualitative impact of the CSC including the quality of the support that is received, levels of satisfaction and the impact of that support.

- $\quad$ The potential for a Social Return On Investment (SROI) type of analysis.

There is also a requirement to provide guidance on what other aspects might be measured in order to demonstrate the impact of the CSC and to provide advice on how information is captured to improve the impact measurement of future activities of the CSC.

The evaluation adopts a desk-based approach using quantitative and qualitative data collected by Weston Park CSC between January 2014 and March 2019. There are a number of stages to the evaluation.

\section{Scoping and assessment of data}

This stage involved an inception meeting with the CSC to familiarise the evaluation team with the project and discuss the range of information collected by the CSC. A subsequent meeting was held to go through the data collected with the CSC and assess what data would be useful for the evaluation.

\section{Analysis of measures across services}

After the initial assessment of the data in the scoping phase, the data was collated so that the measures collected across the services could be analysed. Analysis involved working out the number of contacts and patients helped, the way help was accessed, the type of help received, and the service used. Data was broken down by age, gender, postcode, cancer site and the type of service as appropriate to show who has been helped by the CSC and how they have been helped.

In order to identify the amount of contacts made by individual patients a number of assumptions with the data were made which are detailed in Appendix 1.

\section{Analysis of Pre and Post Course Information}

Pre and post course questionnaires were examined to assess levels of satisfaction with courses and the quality of support received, as well as the impact of support on beneficiaries of the CSC courses. Some courses have utilised an adapted outcome 
star pre and post course measure. This measure was used to assess change and to demonstrate how people have been helped to respond to their illness and deal with the impact it has on various aspects of their lives. However, it was not possible to demonstrate change at an individual level due to the way the data was collected.

\section{Analysis of Qualitative Evidence}

Existing qualitative evidence was reviewed and where possible was employed in the evaluation to supplement the analysis of measures and pre and post course data outlined above. The existing qualitative data is somewhat limited and does not capture the views of all the CSC stakeholders in much detail. The lack of in-depth qualitative material means that it is not possible to use the data to qualitatively assess the impacts and outcomes of the various interventions offered by the CSC.

\section{Financial Gain and Economic Value}

Citizens Advice Sheffield delivers Welfare Advice at Weston Park CSC and produces generic annual reports which detail financial outcomes for a proportion of clients. This figure provides an indication of the financial value of the service to clients. We also calculated the annual economic value that Centre volunteers contributed in 2018 and 2019.

\section{Assessing Impact and Guidance on Future Measurement}

The evaluation has examined the data collected by the CSC to consider the difference it is having on the lives of people affected by cancer who are using the Centre. Weston Park CSC may want to consider collecting additional data and outcome measures in order to assess the value and wider benefit of its services more fully. Some considerations and recommendations on data collection and future measurement are detailed in Chapter 5 of this report.

\section{Reporting and Slide Pack}

The main output from the evaluation is this final report. We have also produced a visual slide pack detailing the findings from the evaluation. It is envisaged that the slide pack will be used by Weston Park CSC to showcase their activities and demonstrate the quality and impact of their work to a variety of different audiences including fundraisers, health professionals and clients.

\subsection{Limitations to the Evaluation}

There are limitations to the evaluation which should be taken into account when reading this report. This is a retrospective evaluation which is attempting to evidence the impact of the CSC over the period from 2014 to early 2019. The evaluation is therefore based on available historic data collected by the Centre on the performance of its services and gathered for its own purposes. The data provides useful feedback on satisfaction with services and courses offered and some indication of the impact of support on beneficiaries. However, the lack of standardised variables, questions and outcome measures used in the data limits the extent to which the evaluation can make comparisons across courses and measure change over time. The evaluation was unable to look at individual level data to measure change. The Centre has made improvements to its database and data collection, but only recently started using a unique identifier on its database. This means data is analysed at an aggregate level, we have also had to make a number of assumptions when identifying the amount of contacts made by individual patients 
(see Appendix 1) and it has not been possible to identify the number of different services and/or courses an individual has taken up.

Finally, some of the data collected on feedback from courses and services is only available for small numbers of people. 


\section{Levels of Activity and Use of Weston Park CSC}

\subsection{Levels of Activity at Weston Park CSC}

In total there were 60,065 recorded contacts with the CSCS between January 2014 and March 2019. Most users contacting the Centre over this period were from the South Yorkshire region, with around three quarters of all enquiries coming from people living in Sheffield. While predominantly serving the local region, the Centre receives a sizeable number of enquires and contacts from across the UK (see Figure 3.1).

Figure 3.1: Weston Park Cancer Support Centre contacts across the UK, local authority

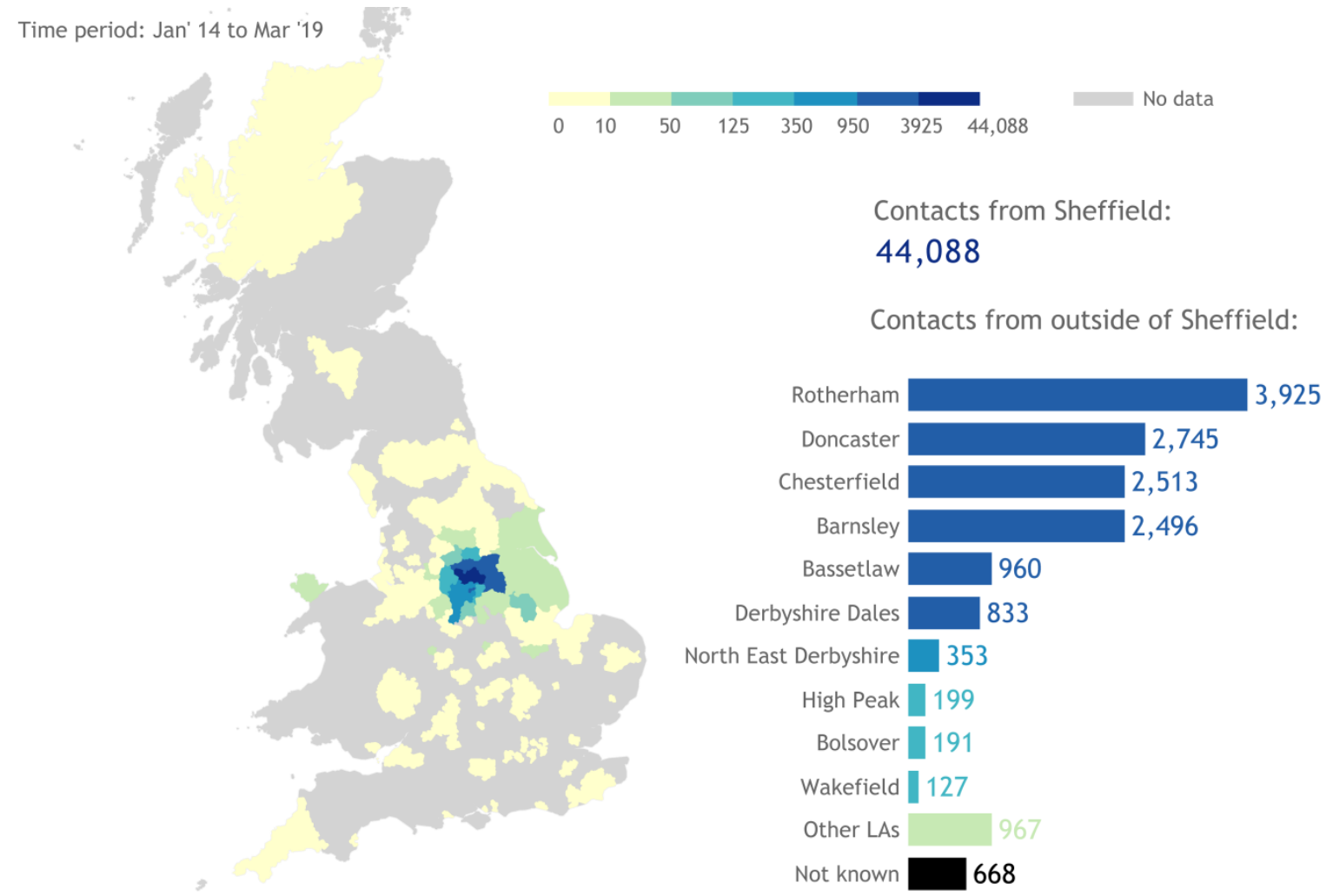

Contains Ordnance Survey data @ Crown copyright and database right 2019 // Geographies: Local Authority // Source: Weston Park Cancer Support Centre

Figure 3.2 below shows that since 2014 the level of activity at Weston Park CSC has risen considerably. Between 2014 and 2018 the number of enquiries and contacts at the Centre increased by $40 \%$ from 9,500 in 2014 to 13,300 in 2018 . The average 
number of enquiries per month in 2014 was 796 and by 2018 was 1109 with the busiest months typically being July, September, October and November. From 2014 to 2018 the number of drop-ins increased by $31 \%$, attending courses by $26 \%$ and telephone enquiries $26 \%$, although overall as a proportion of all contacts the different modes of contact remained steady, see Figure 3.3.

The CSC deals with enquiries throughout the week and data shows that the Centre is usually very busy between $10 \mathrm{am}$ and 12 noon each day, with particularly busy times being Tuesday and Wednesday at 10am-11am, Wednesday $1 \mathrm{pm}-2 \mathrm{pm}$ and Tuesday 2pm-3pm. Drop-in appointments occur throughout the day usually between $10 \mathrm{am}$ and $3 \mathrm{pm}$ but Wednesday 10am-11am, Thursday 1pm-2pm and Friday 2pm$3 \mathrm{pm}$ are less busy than other days at these times.

Figure 3.2: Enquiries and contacts with Weston Park CSC

\section{Enquiries with Weston Park Cancer Support Centre}

Total amount of contacts with the Cancer Support Centre, since 2014
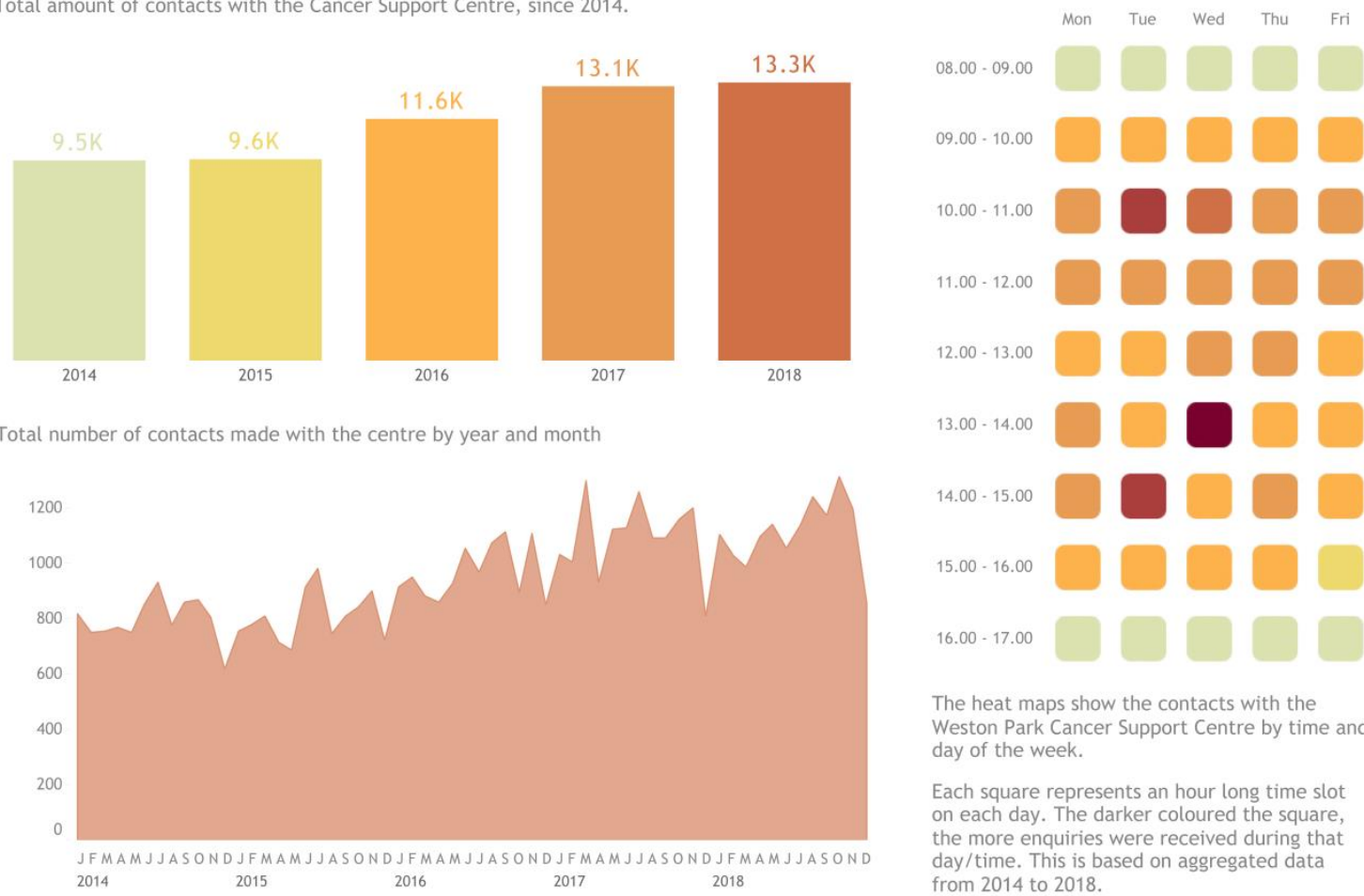

Total number of contacts made with the centre by year and month

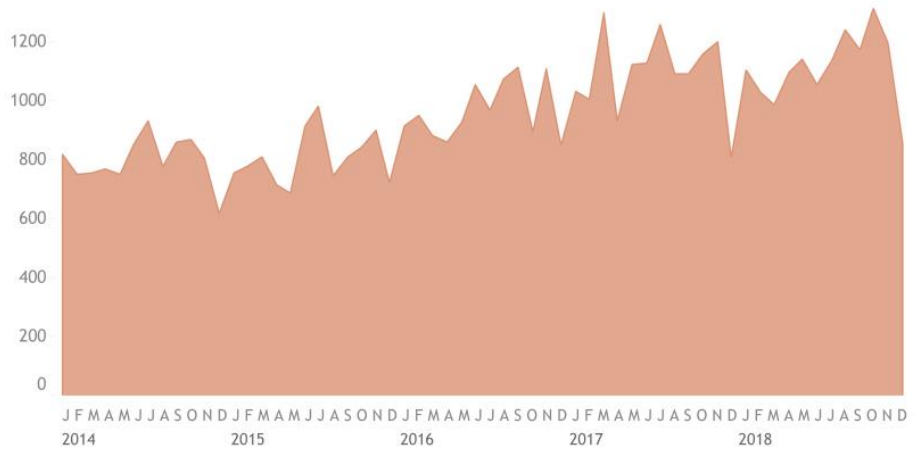

from 2014 to 2018 
The heat maps show the density of contacts with the Weston Park Cancer Support Centre by time and day of the week, for different modes of contact. Each square represents an hour long time slot on each day. The darker coloured the square, the more enquiries were received during that day/time. This is based on aggregated data from 2014 to 2018.

This visualisation looks at drop-ins, attendances at courses, telephone contacts compared with all other modes of contact.

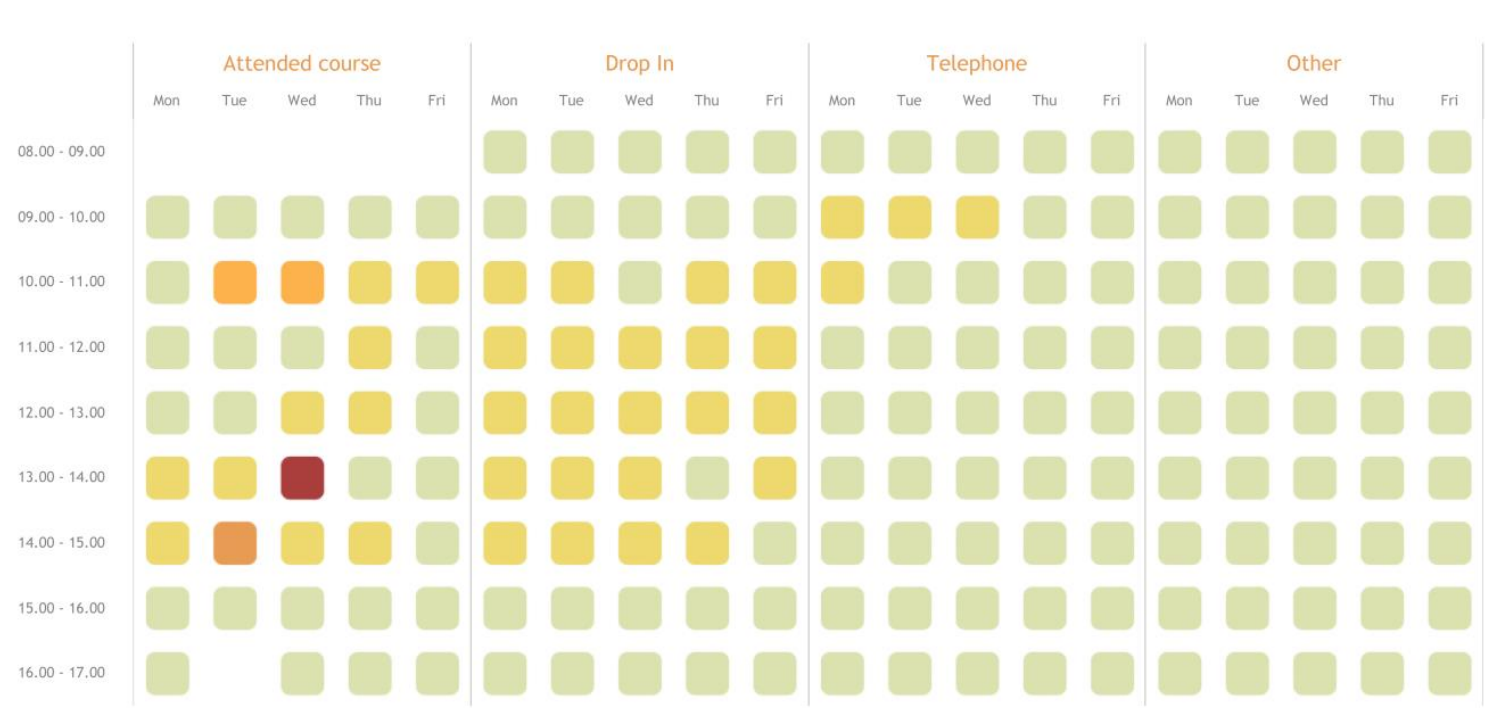

Of all these enquiries around $58 \%$ were made by patients, $24 \%$ by carers, $8 \%$ by relatives and $8 \%$ by health care professionals. People were usually engaging with the CSC because they were attending a course or service (36\%), using the Drop-in service $(35 \%)$ or making a telephone enquiry $(27 \%)$. As well as attending a course or service (36\%), the main reasons for contact included emotional support (29\%), welfare benefit enquiry (26\%) and requests for information about local support and groups (23\%). Patients at Weston Park CSC.

\subsection{Patients at Weston Park CSC}

If we look specifically at patient activity during this period, we estimate that 6,840 patients made over 32,000 contacts with the Centre which equates to an average of 4.8 enquiries per patient. Figure 3.3 below provides a detailed summary of all patient enquiries and contacts in 2014 and 2018, the demographic characteristics of patients and their cancer diagnosis. Typically, most patient contacts required either Level 1 (0-15 minutes Drop in/referral/telephone enquiry/informal chat) or Level 2 (15-30 minutes Assessment of information needs verbal information backed up with written information if required, appropriate level of psychological support) intervention. Level 2 interventions increased from 59\% to $64 \%$ of all patient contacts between 2014 and 2018 . 
Figure 3.3: Patients at Weston Park CSC

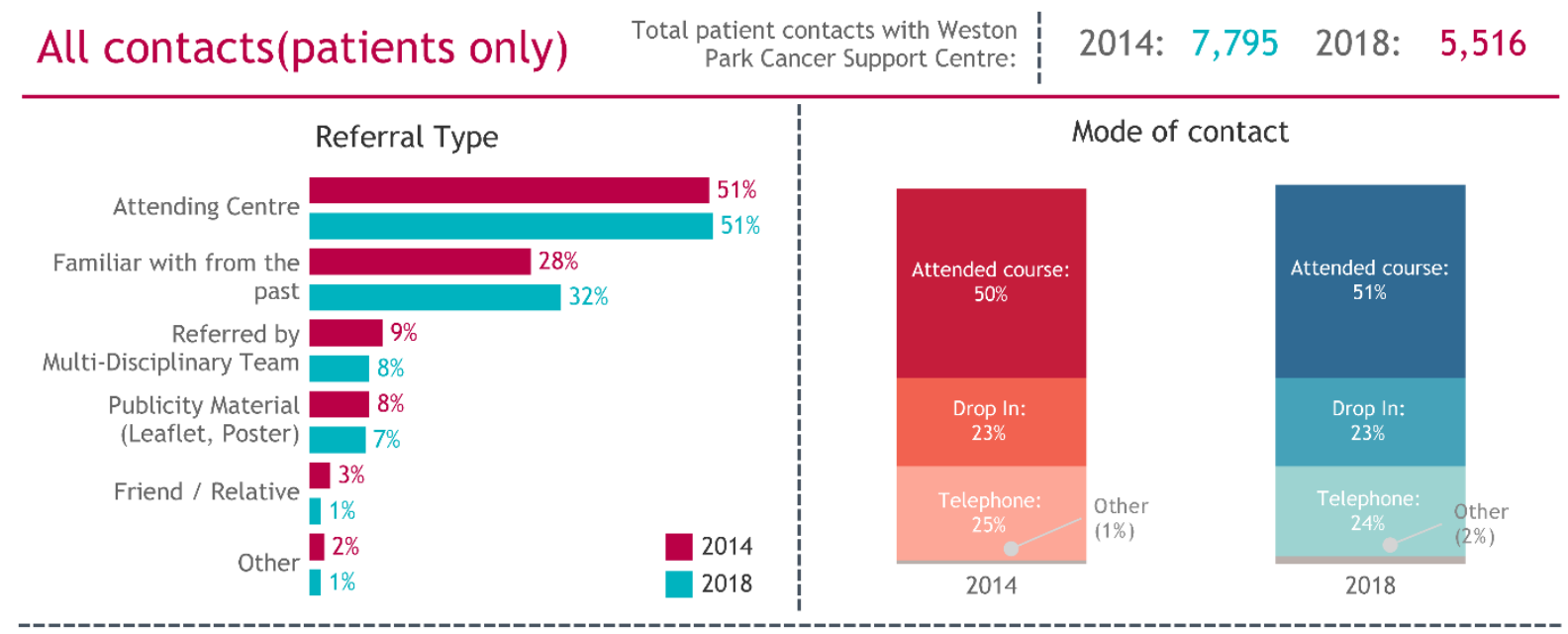

Gender

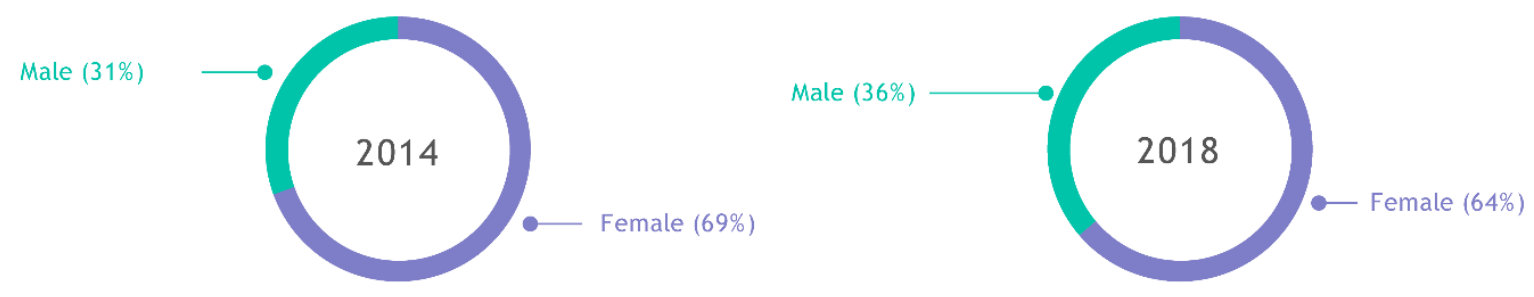

Age range

2014

2018

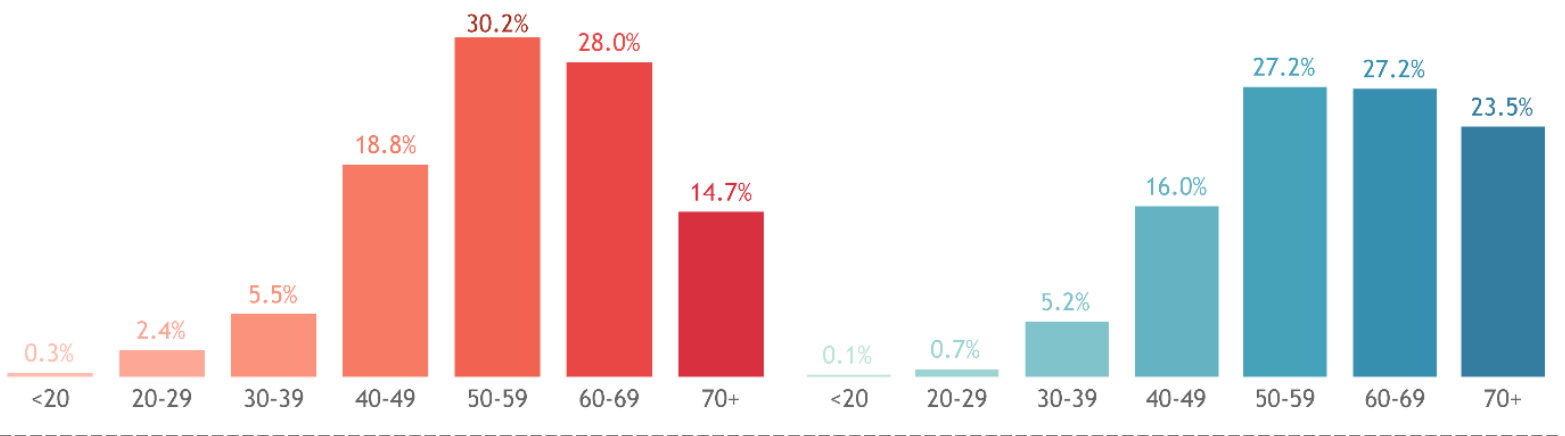

Ethnicity

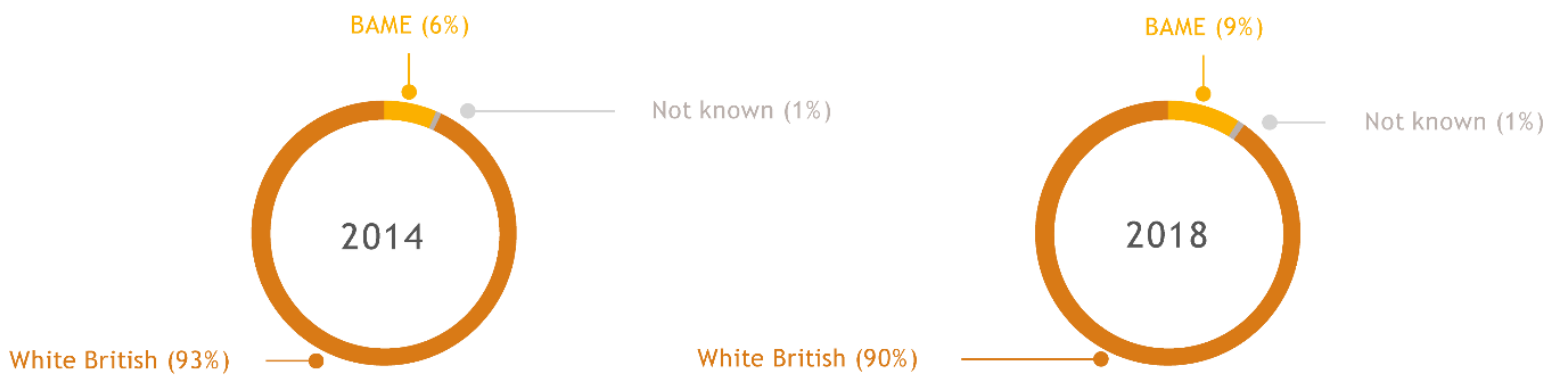




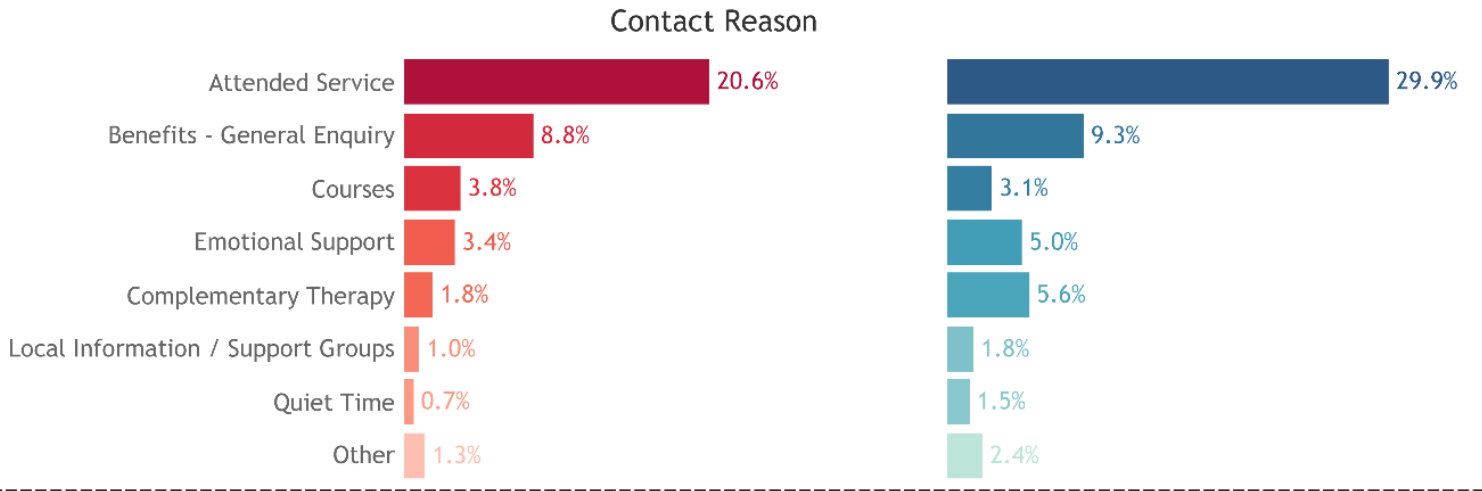

Levels of involvement

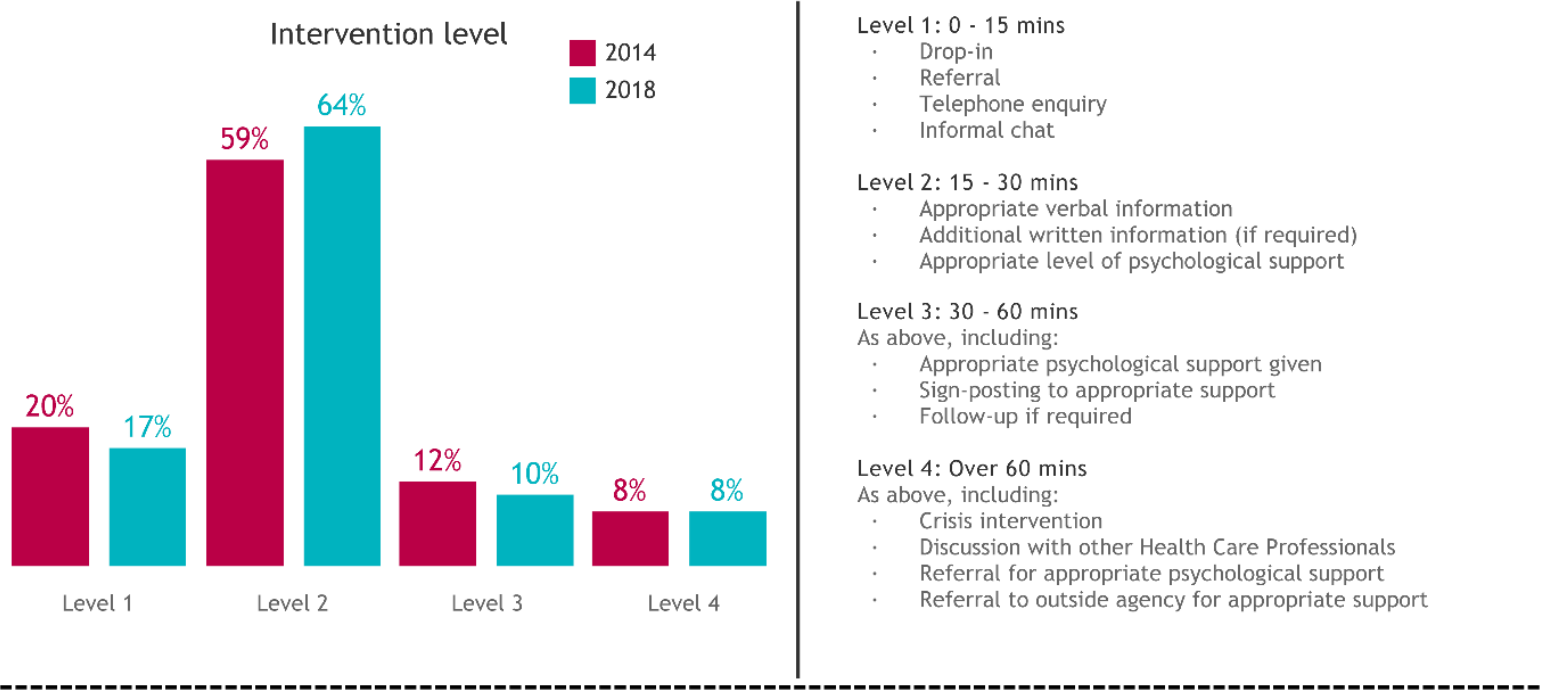

Diagnosis

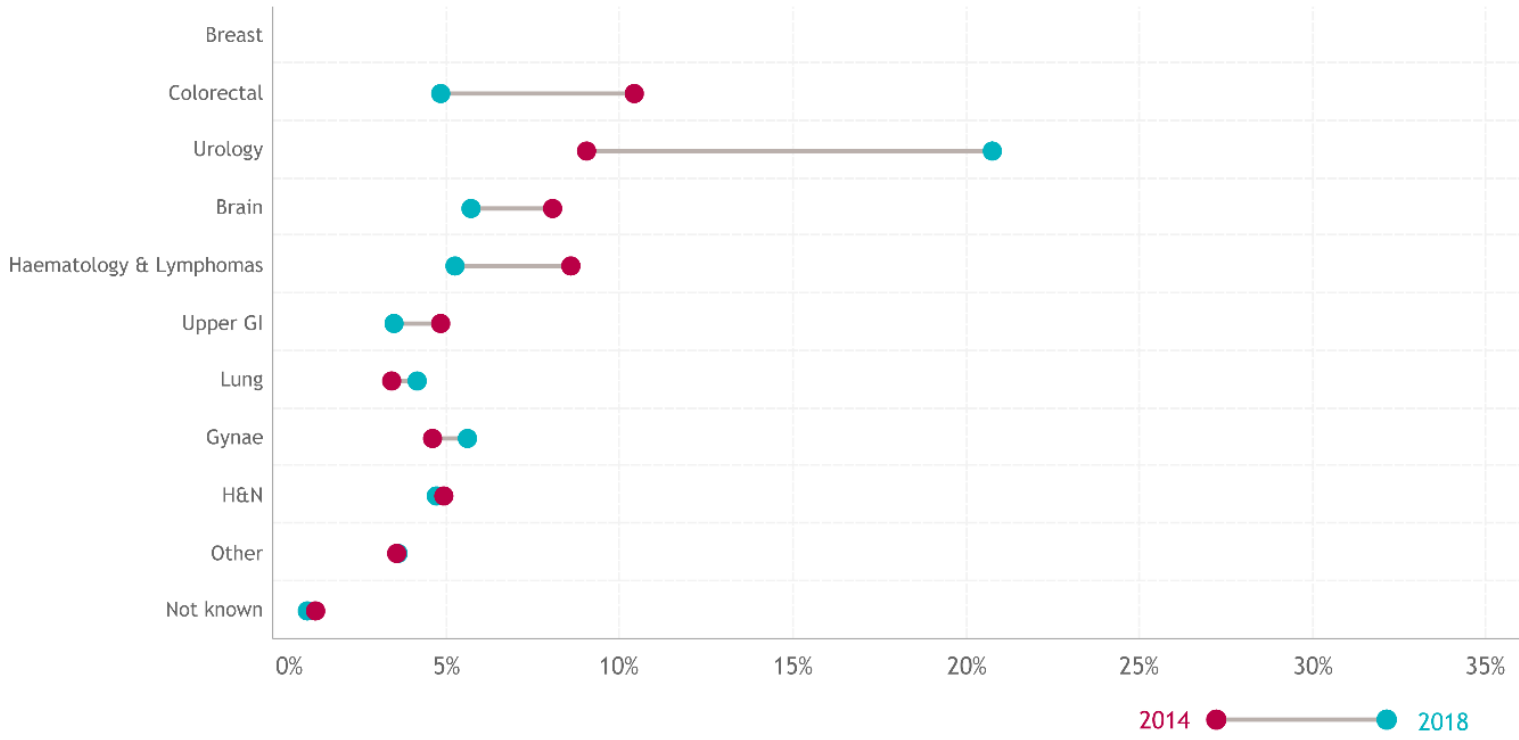

When examined in relation to new cases of cancer in the Cancer Alliance area of South Yorkshire, Bassetlaw, North Derbyshire and Hardwick and for England over the period 1995-2015, the results outlined in Figure 3.4 and Figure 3.5 suggest that men and those aged over 60 are underrepresented at the CSC and that there is a higher proportion of people in the 40-59 year old group. Nationally cancer incidence 
rates are significantly lower in males than females in younger age groups and significantly higher in males than females in the older age groups ${ }^{2}$.

Figure 3.4: National and local cancer prevalence and Weston Park CSC use by sex

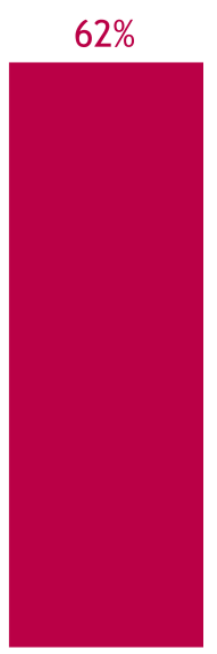

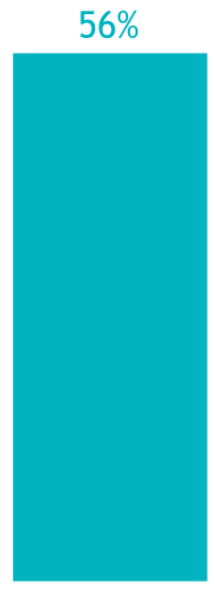

Female
- CSC use (patient only)(2014-19)

South Yorkshire, Bassetlaw, North Derbyshire and Hardwick (Cancer Alliance) (1995-2015)

England (1995-2015)
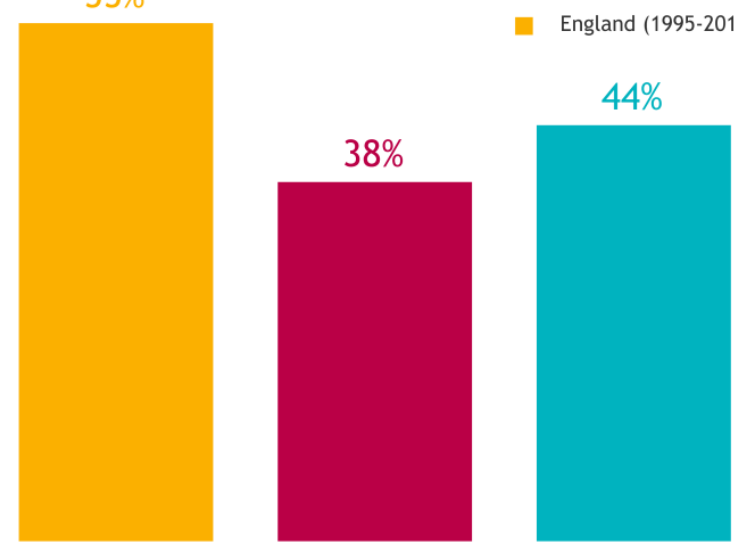

$45 \%$

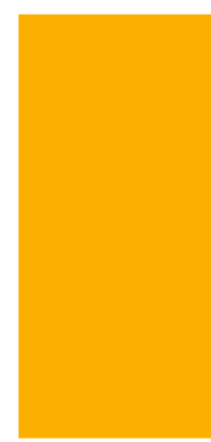

Male

Figure 3.5: National and local cancer prevalence and Weston Park CSC use by age

CSC use (patient only)(2014-19)

South Yorkshire, Bassetlaw, North Derbyshire

and Hardwick (Cancer Alliance) (1995-2015)

- England (1995-2015)

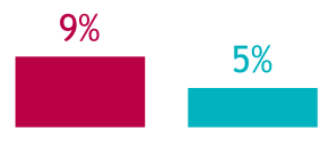

$<40$
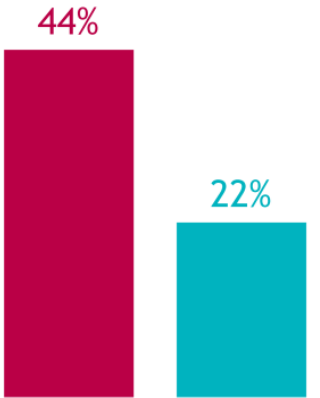

40-59
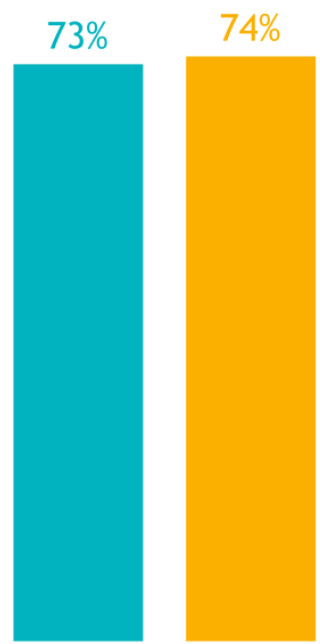

$60+$

With regard to cancer type, most patients using the CSC broadly reflect the picture across the Cancer Alliance area and England, that of people living with cancer, prostate is the most prevalent type in men and breast in women ${ }^{3}$. Whilst breast cancer is the most common cancer in the UK accounting for $30 \%$ of all new cancer cases, of the patients using the Centre, $36 \%$ have a breast cancer diagnosis (see Figure 3.6). Whilst data suggests that patients with breast cancer are

\footnotetext{
2 http://www.ncin.org.uk/view?rid=3579

3 https://www.cancerresearchuk.org/sites/default/files/achieving world-class cancer outcomes a strategy for england 2015-2020.pdf
} 
overrepresented at the Centre, patients with other cancers such as urology, colorectal and skin cancers may be underrepresented.

Referrals to Weston Park CSC frequently come from the Hallamshire and Weston Park hospitals and $35 \%$ of patient referrals are made by Multi-Disciplinary Teams (MDTs). Referral patterns for different cancer types will be directly influenced by the awareness and knowledge the different cancer teams and health professionals have of the CSC. Patients attending departments based at the Northern General may be less likely to make ad hoc visits to attend the Centre.

Figure 3.6: National and local cancer prevalence and Weston Park CSC use by cancer type

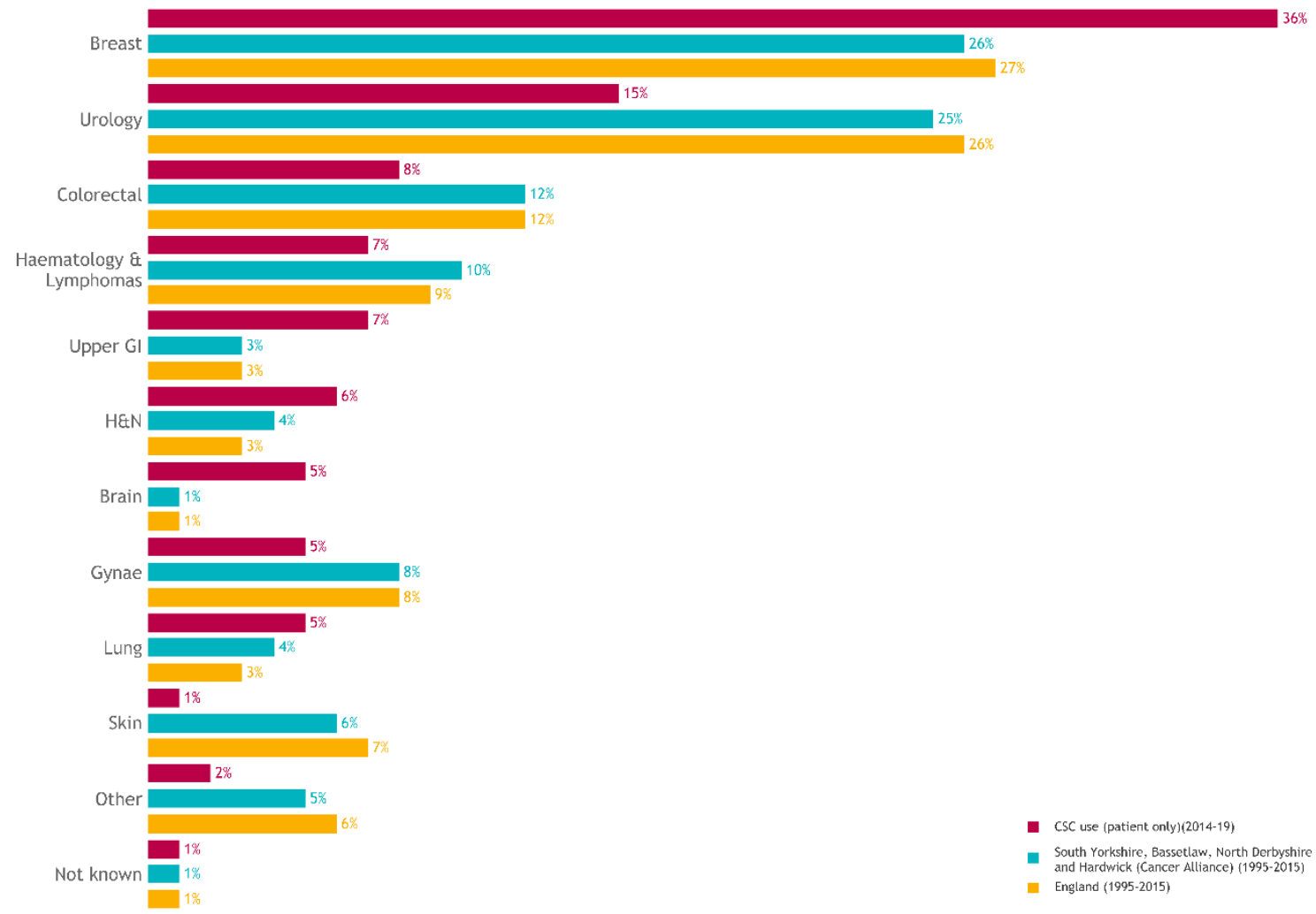

It is more difficult to estimate whether Black and Minority Ethnic (BAME) people are underrepresented at the Centre as there is less up to date information on new cases of cancer incidence and ethnicity. Overall the incidence of cancer in the BAME population is lower than that in the white population but this varies for different BAME groups and cancer types. For example, black males are up to three times more likely to get prostate cancer than white males. Black people are nearly twice as likely as white people to get stomach cancer. Asian people are up to three times more likely to get liver cancer than the white population ${ }^{4}$.

Given that $13 \%$ of people in Sheffield come from BAME communities ${ }^{5}$ and around $9 \%$ of patient enquiries in 2018 were from someone belonging to such a group, this is something which requires further investigation.

The map in Figure 3.7 also shows that most patients come from nearby the Centre. However, patients do not necessarily come from areas within the city which

\footnotetext{
${ }^{4}$ (NCIN (2009). Cancer Incidence and Survival by Major ethnic group. England, 2002-2006.

http://www.ncin.org.uk/view.aspx?rid=75)

${ }^{5}$ https://www.ukpopulation.org/sheffield-population/
} 
experience the highest prevalence of cancer, typically the cancer incidence rate nationally in the most deprived groups is higher than the cancer incidence rate in the least deprived groups ${ }^{6}$. Inequality in cancer incidence by deprivation is a major health concern and also mirrors varying prevalence of risk factors such as increased smoking and poor diet etc. Nationally, the most deprived wards tend to have higher rates of certain cancer types such as lung cancer, liver cancer and male mouth cancer whereas the least deprived areas have higher levels of prostate and breast cancer reflecting the higher uptake of screening tests in the $20 \%$ least deprived population ${ }^{7}$.

When we look at where patients come from and cancer incidence in Sheffield it is apparent that there are wards where people experience a high frequency of cancer but low use of the Centre. These include some of the most deprived wards such as Firth Park, Southey, Burngreave, Darnall, Arbourthorne and parts of Gleadless Valley. Patients living in some deprived wards with a high incidence of cancer such as Manor and Castle are utilising the Centre more than those living in other deprived wards. This may reflect the availability of local provision, ease of transport access and awareness of the CSC.

Figure 3.7: Cancer incidence compared with support centre patients in Sheffield

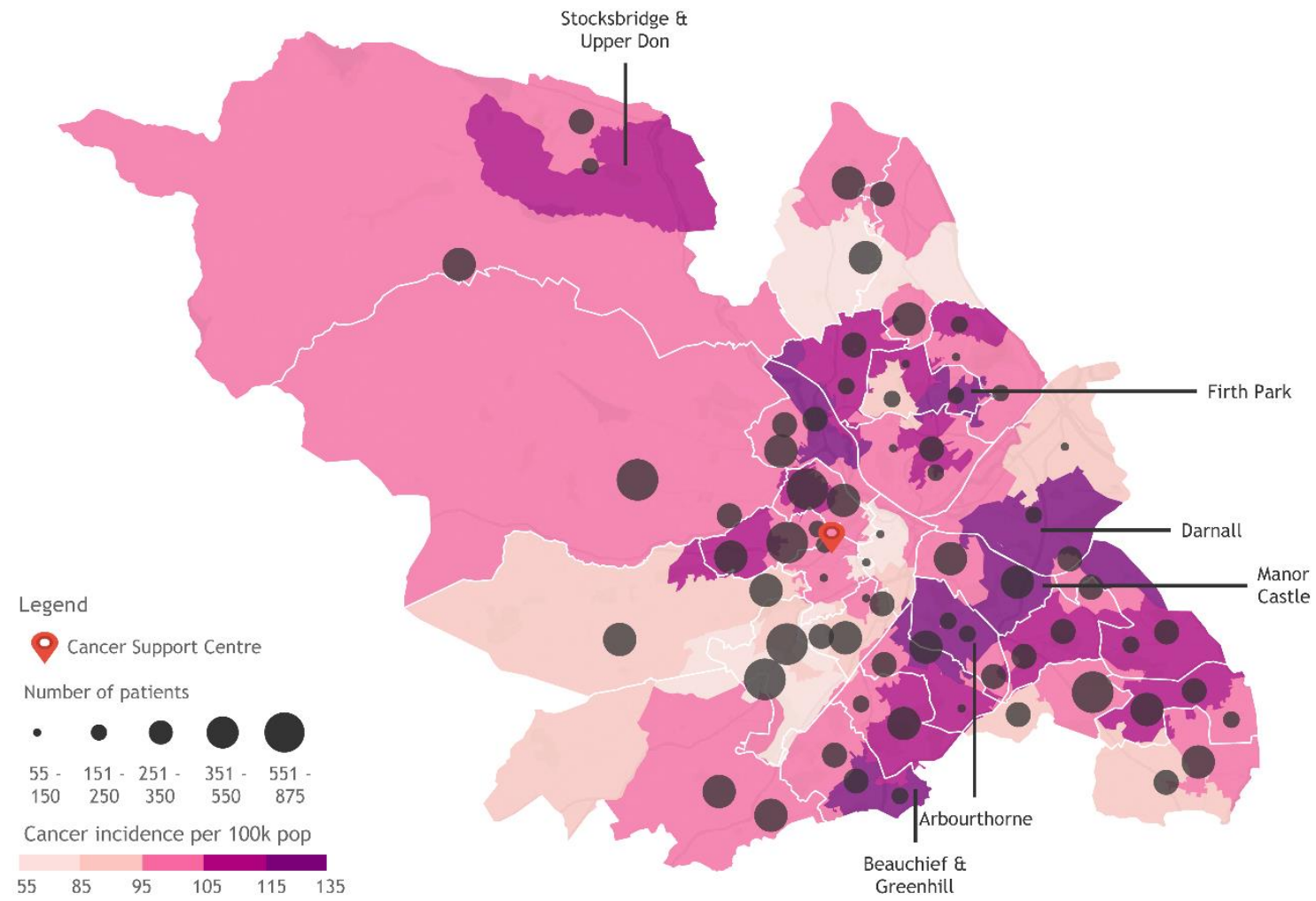

Contains Ordnance Survey data (C) Crown copyright and database right 2019 // Geographies: MSOAs // Sources: NHS England and Weston Park CSC

\footnotetext{
${ }^{6}$ NCIN (2014). Cancer by Deprivation in England Incidence, 1996-2010. http://www.ncin.org.uk/about ncin/cancer by deprivation in england ${ }^{7} \mathrm{NCIN}$ (2014). Cancer by Deprivation in England Incidence, 1996-2010. http://www.ncin.org.uk/about ncin/cancer by deprivation in england
} 


\subsection{Summary}

Overall, the results presented in this chapter demonstrate the rapid increase in the volume of work that the CSC is undertaking. The CSC mainly serves Sheffield and the South Yorkshire region but receives enquiries from other parts of the UK too. However, there are certain groups of people (including men, the over 60s and BAME populations) and deprived parts of Sheffield experiencing high levels of need currently not being met by the Centre. Though the cancer patients using the Centre are typical of most people living with cancer in the UK, there are people experiencing certain types of cancer underrepresented at the Centre. Some of these cancer types are more likely to be experienced by the most disadvantaged groups. 


\section{The Quality and Impact of Weston Park CSC Services and Courses}

As mentioned, Weston Park CSC offers a wide range of services and courses to patients, carers and family members, details of which are outlined in Chapter 1 of this report. Feedback on these courses and services is regularly gathered by the Centre. This information has formed the basis of our assessment of the quality and impact of the activities offered.

\subsection{Numbers Attending Courses}

Large numbers of people attended courses at the CSC between 2014 and 2018. Data from the CSC shows that:

- 2414 people went to a Craft Afternoon;

- 5010 people received Welfare Advice;

- 454 people attended the Bereavement Course;

- 219 people went on the Carers Course;

- 1304 people attended Positive About Life.

Example data and comments from course evaluations are presented below.

\subsection{Quality and satisfaction with services and courses}

Overall, people utilising the various services at the CSC reported high levels of satisfaction with the service they received. 


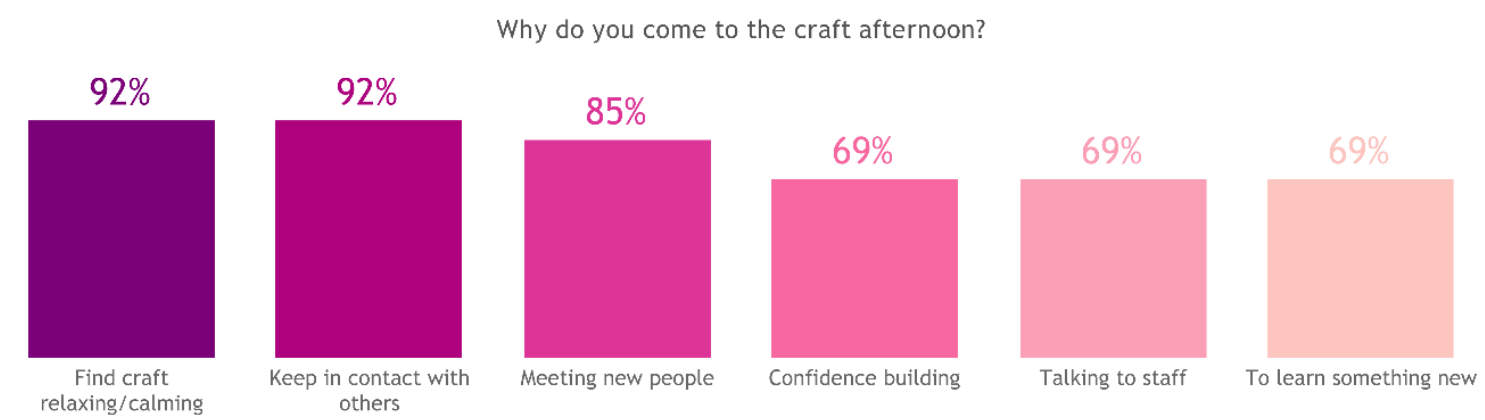

Participants who responded positively, negatively or neutrally to the following questions:

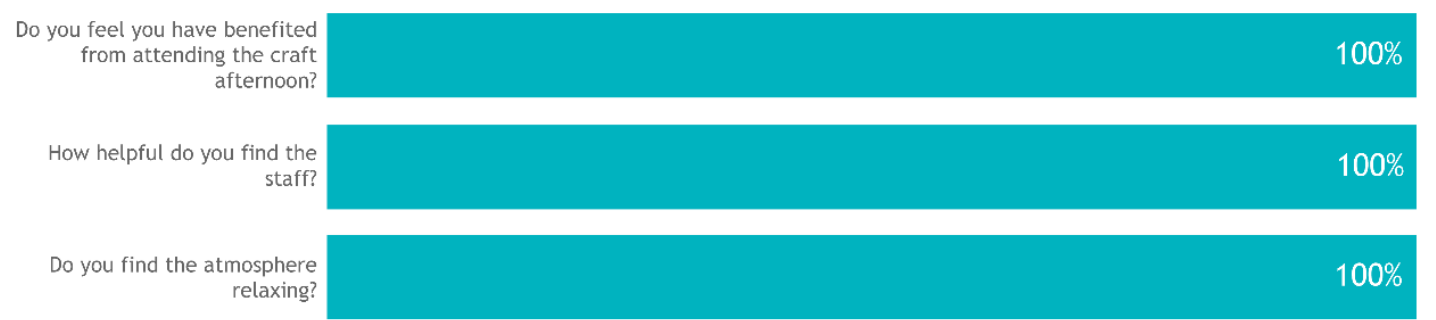

Those attending services like the Coffee Morning and the Craft Afternoon (see Figure 4.1 above) reported a variety of benefits and much needed social and emotional support. Such services also presented the opportunity for attendees to talk to Centre staff and find out about additional information and support if needed.

Although the Centre was busy, people attending received a warm welcome and the Centre was generally regarded as relaxing.

We were immediately made to feel welcome.

Always greeted with a smile, made very welcome.

Very pleasant and inviting.

The sitting area is comfy, friendly and relaxing.

Staff members and volunteers were very helpful and friendly. Typical comments included:

Everyone so supportive.

Very friendly and helpful.

Always been extremely helpful. Staff are very pleasant.

It was clear from the reports of those who were contacting the Centre through telephone enquiries and using the Drop-in service that these services were very informative, and people received the relevant information they needed. 
I have called the Centre again for more help and advice for family members, as you were very helpful before.

Lots of information available and relevant.

I wish I had come here earlier; I would have benefitted from all the info.

Information on the walls, and just asked if I needed (anything) in particular.

Wouldn't hesitate to ring again with any query.

I wasn't sure what I wanted/needed but made comfortable and left with relevant information.

Many people contacting the Centre needed specialist advice about benefits and legal issues. Almost half of the patients contacting the Centre were enquiring about benefits. (Welfare advice is provided via a contract with Citizens Advice and legal advice is provided by visiting solicitors at the Centre). Both these services were regarded as extremely helpful, with useful information explained in a way which was easy to understand, and clients were very satisfied with the advice received and overall service. A particular aspect of the Welfare Advice service that was valued was its availability on the Haematology Unit. 
Figure 4.2: Welfare Advice Evaluations

Total attendances (2014-18): 5,010 Participants: 98 Evaluations:66

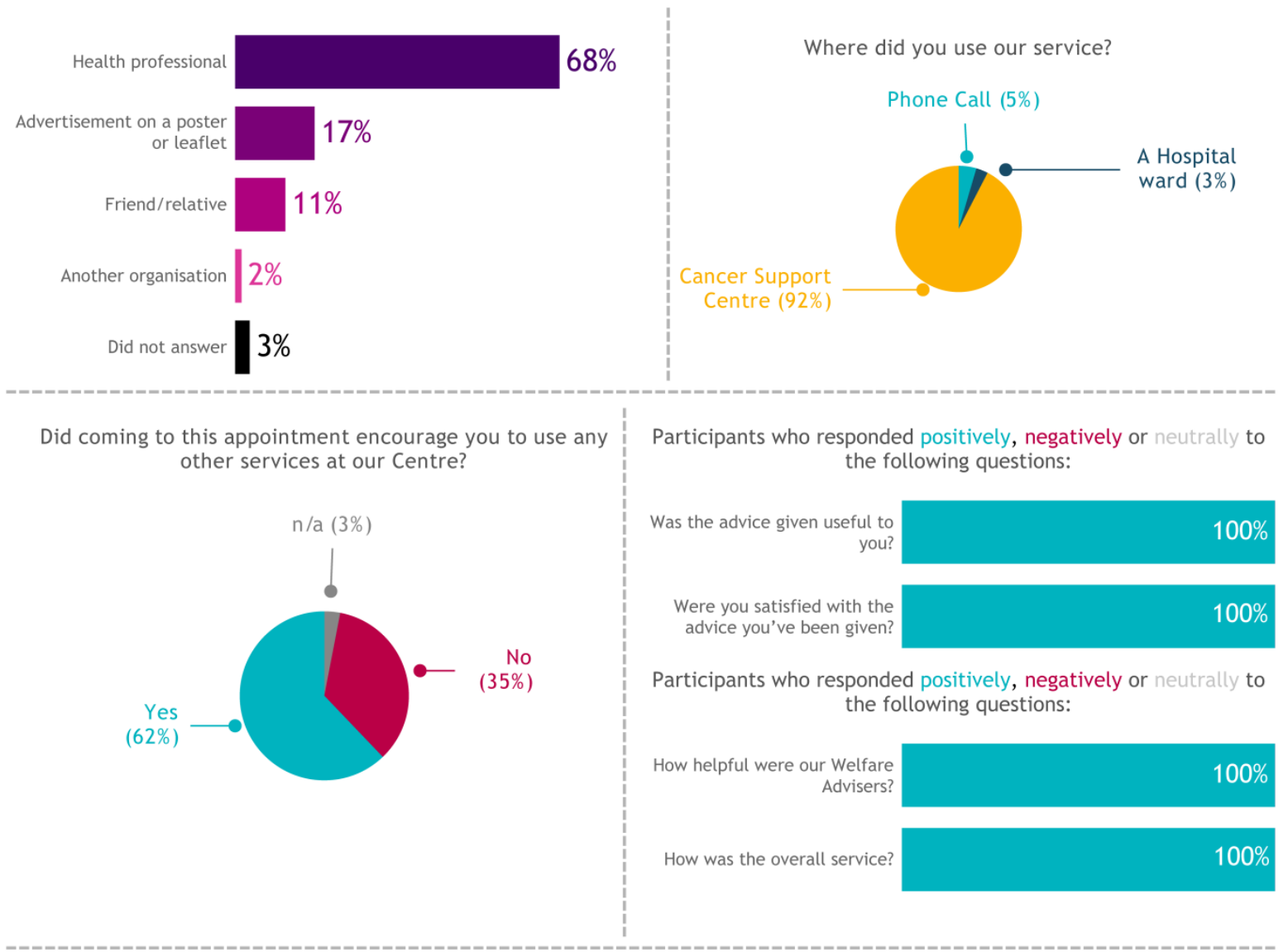

Participants felt improvements may happen, as a result of the advice they received, in in the following areas:?

$53 \%$

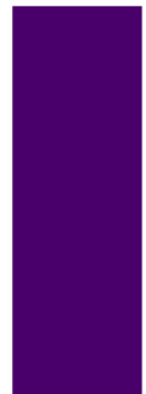

Household income

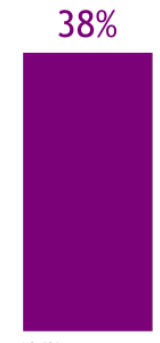

Ability to cope with financial matters

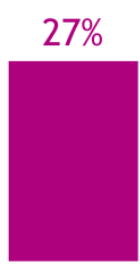

Quality of Life

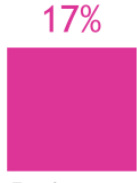

Employment matters

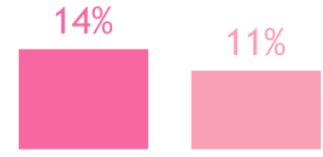

Social life
Housing situation Family or other issues

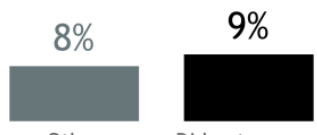

Other

Feedback on all the various courses delivered at the Centre was also extremely positive (see Figure 4.3 and Figure 4.4 as examples), most of the sessions delivered by healthcare staff were useful, almost all those who attended courses felt they had benefited and appreciated the supportive nature of the groups. For example, participants who attended the Bereavement course (see Figure 4.3) reported a much greater recognition of their feelings of grief and found the experience of sharing their experiences of grief with others who are going through a similar experience useful.

Group interaction has been really beneficial.

I am not the only one and understand my feelings are normal. 
Made me realise that what I felt and how I dealt with things is normal.

l'd read about the grieving process before, but the course facilitated discussion, which was really helpful.

Comforting to know you are not alone in your feelings and it's liberating to be really honest about some feelings that aren't nice and can't be shared with friends or relatives.

\section{Figure 4.3: Bereavement Evaluations}

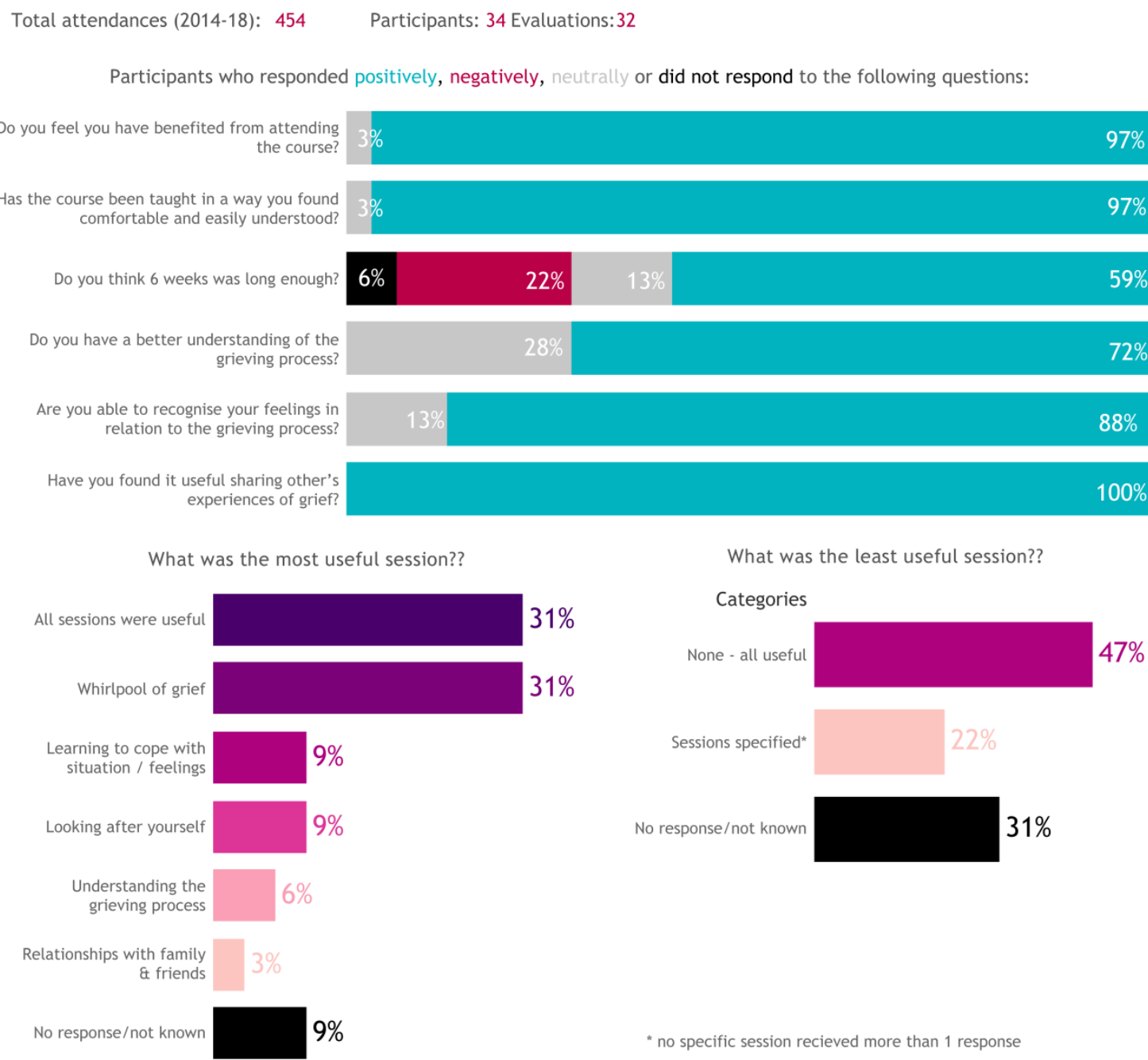

In terms of improving courses there was an indication from some participants that the Bereavement course and Carers course were not long enough, and they felt they would have benefited from a slightly longer course. (The Carers course figures should be treated with some caution as only for 8 participants).

I think another 2 sessions would be of benefit - the course invites a lot of discussion.

More time would have been beneficial.

By adding 1 or 2 sessions. The course content and added discussions (a very important part) take longer than 6 weeks. 
Figure 4.4: Carers Evaluations

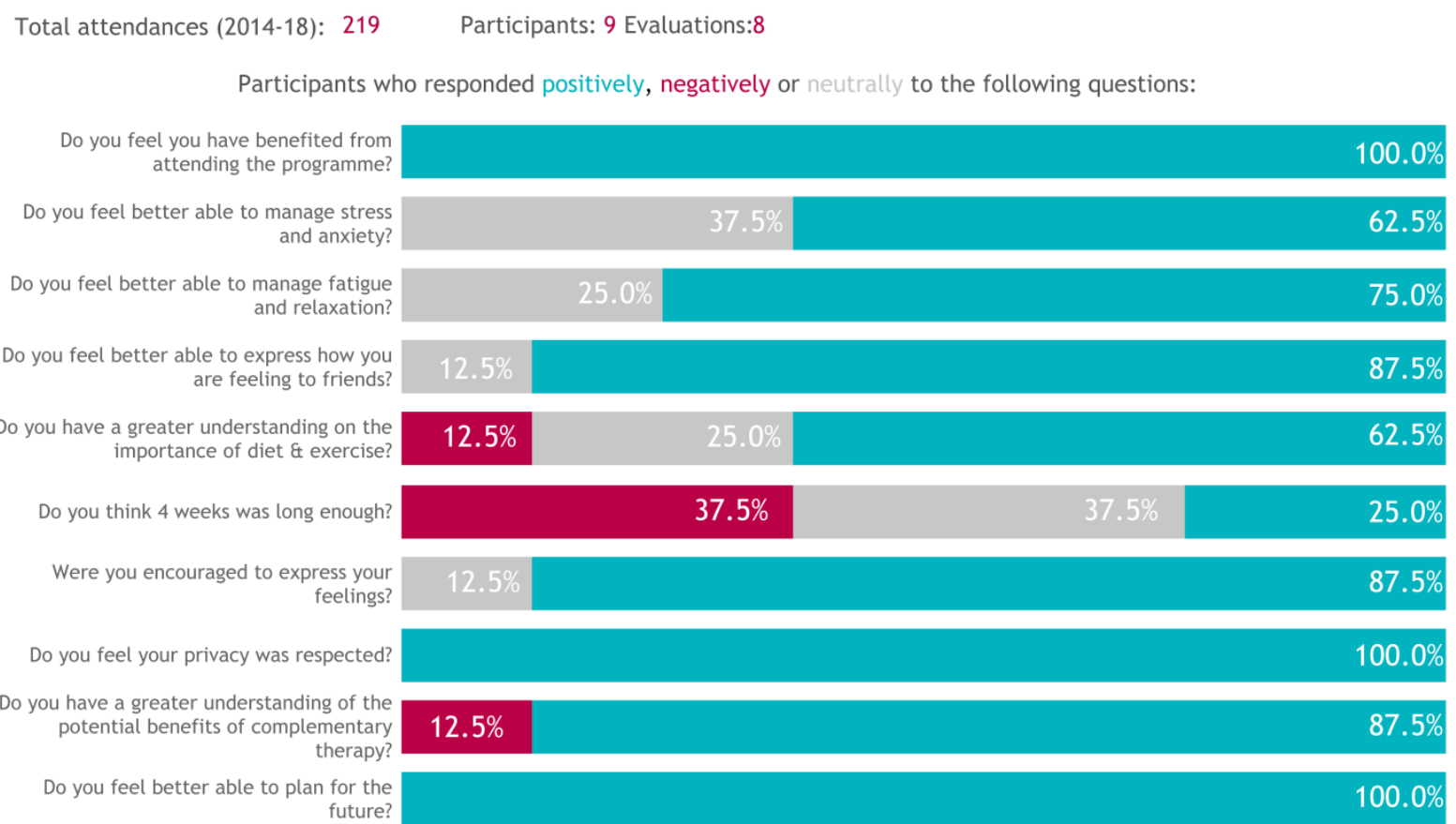

Some participants who had attended the Auricular Acupuncture course also commented they would be willing to pay for continuing sessions at the Centre.

The service was brilliant, just a shame we could not pay to have treatment here.

It's a shame the treatment can't continue here and actually pay for treatment rather than have to go elsewhere. The other ladies on the session today all agreed that they wish they could pay to carry on here.

\subsection{The impact of services and courses}

A major impact of the services and courses delivered by the CSC was associated with the social value of meeting people and having contact with others who were in a similar situation. Those attending courses and activities such as the Coffee Morning and Craft Afternoon welcomed the opportunity of talking with others, meeting new people and making friends.

I found another benefit of the service was having a chance to meet other women in the same situation. (Ladies Acupuncture).

To meet and chat with other people. (Coffee Morning).

Meeting very friendly people. Also, talking to people who have experienced the same. (Coffee Morning).

Socialising with others. (Craft Afternoon).

Contact with the Centre and use of services and courses resulted in people feeling more supported and less isolated and alone.

The group has shared many stories and been a support to each other. (Bereavement Course). 
Thank you, it helps so much to know that you are there, even if I don't actually call in. Stops me from feeling so isolated. (Bereavement Course).

Nice to know there is always support if it is needed. (Coffee Morning).

Not feeling so alone (Bereavement course).

It helped me to feel less alone and that other people understand. (Positive About Life Course)

Courses also provided an opportunity to learn something new, share skills and helped to boost the confidence and self-esteem of those attending.

Learning new skills and sharing skills and ideas. (Craft Afternoon)

A great deal, making me more confident. Teaching the breathing helped, thinking of the present. (Mindfulness course).

I have been given a lot of advice and pointers in which I can help myself to focus on. A new way to experience things all round. (Mindfulness course)

This has been extremely beneficial to me and I now feel that I can move on positively and it has made me feel stronger and (helped with) getting my confidence back. Thank you!! (Bereavement course)

This is backed up by the average pre and post outcome star scores for those attending the Bereavement course and Carers course which show that people's sense of achievement about learning something new was one of the main improvements reported (see Figure 4.5 and 4.6).

\section{Figure 4.5: Outcome Star - Bereavement Course}

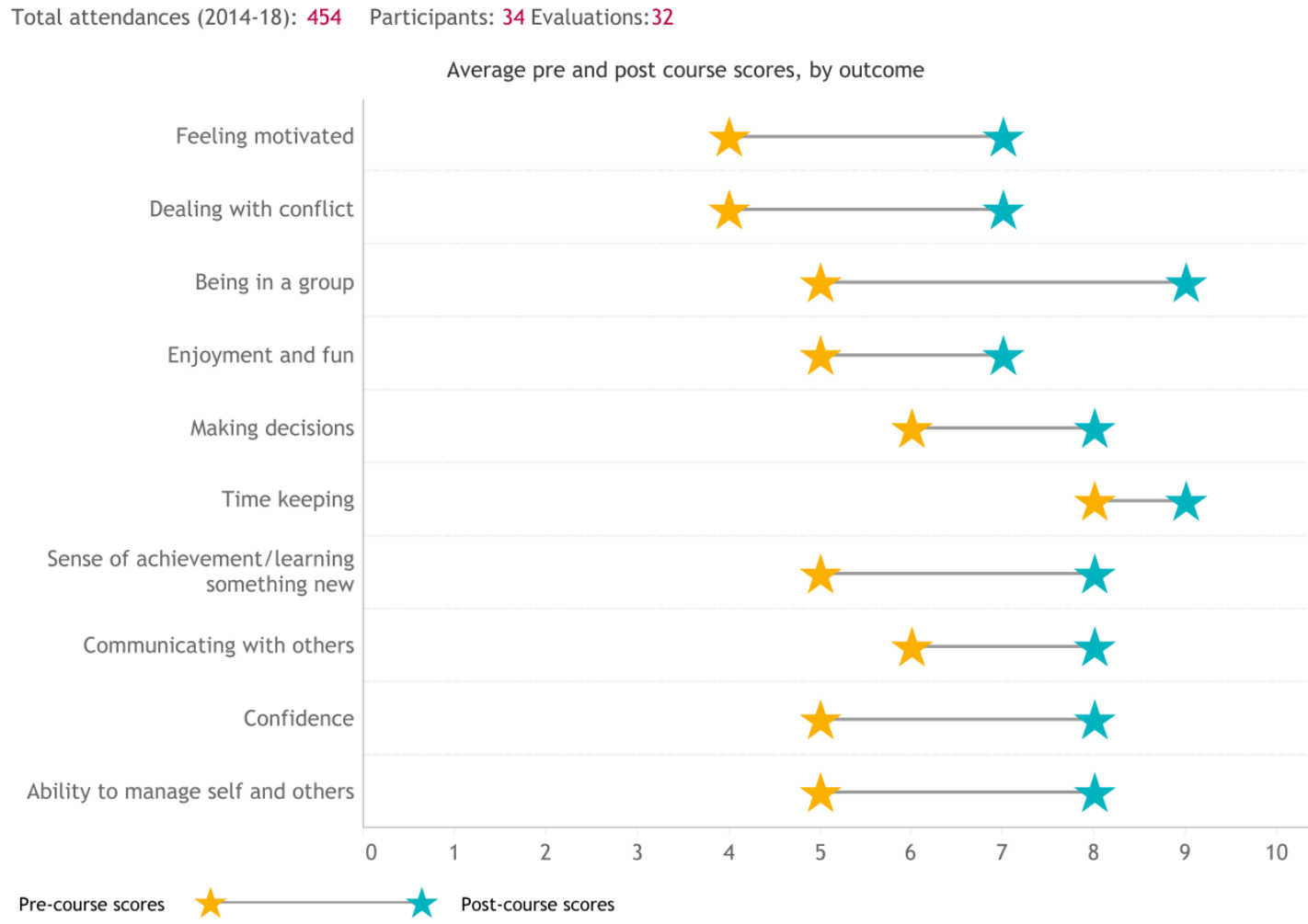


Figure 4.6: Outcome Star - Carers Course

Total attendances (2014-18): 219 Participants: 9 Evaluations:8

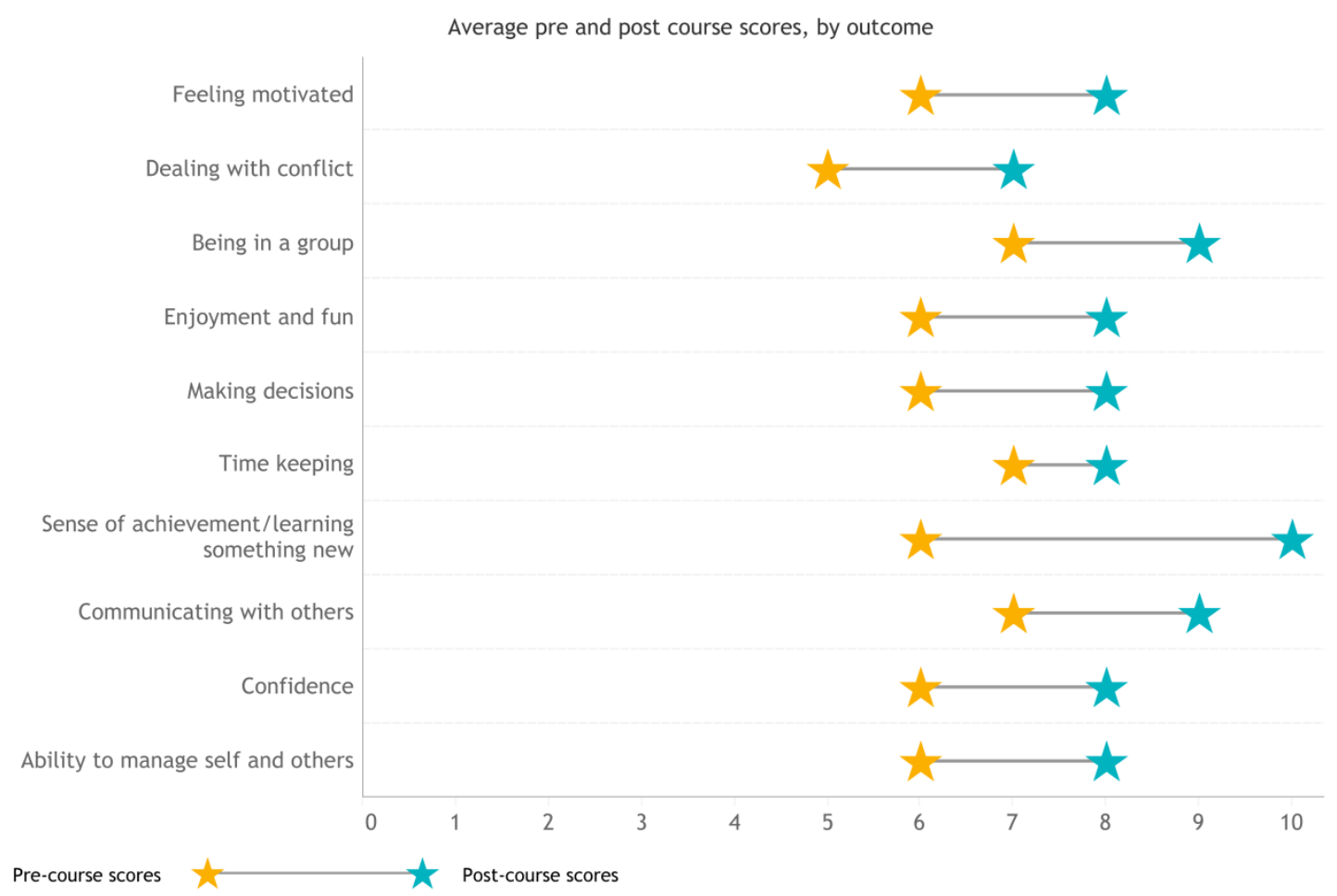

After attending services and courses most people reported having less stress and anxiety and felt much calmer and happier as a result. Practices such as Mindfulness and Acupuncture helped people to relax and improved their ability to cope with illness and other related issues. Typical responses from people attending these services included:

I feel more able to deal with day to day activities, I feel more relaxed, positive and anxiety is almost gone.

Calmness, ability to cope especially with the 'what if's'.

I feel more positive, happier and less stressed.

The ability to calm my thoughts and feelings.

Feeling generally more relaxed -Thank you!

General relaxation, switching off from the tension of being ill. Making life more manageable and normal. It's a lovely relaxed atmosphere, a real help for me.

Common benefits from the Ladies Auricular Acupuncture course also included a reduction in the number and severity of hot flushes and more and improved quality sleep.

These benefits are exemplified by the available pre and post course data for those attending the Positive About Life course, the most positive improvements to people's lives were in coping with stress and anxiety and managing fatigue, sleep and relaxation (Figure 4.7 ). 
Figure 4.7: Positive About Life (PAL) Evaluations

Total attendances (2014-18): 1,304 Pre-course // Participants: 23 Evaluations:20 Post-course // Participants: 23 Evaluations:16

Participants who responded positively, negatively, neutrally or did not respond to the about different areas of their life:

Coping with stress and anxiety

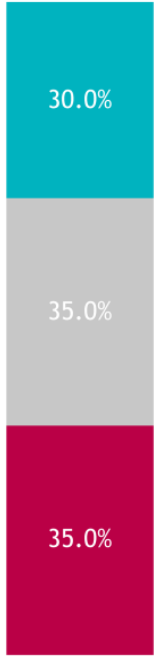

Pre

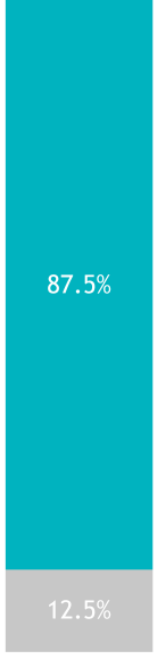

Post
Managing fatigue, sleep

and relaxation

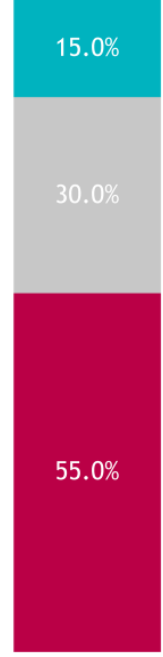

Pre

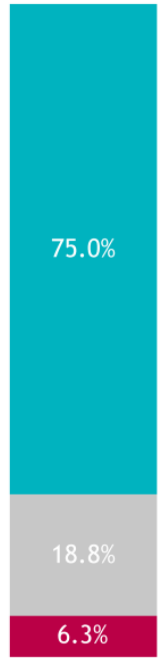

Post
Activity Levels

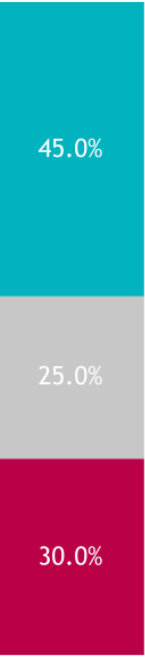

Pre

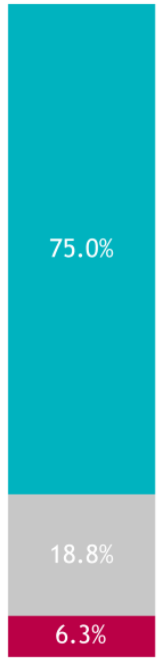

Post
Understanding of best diet

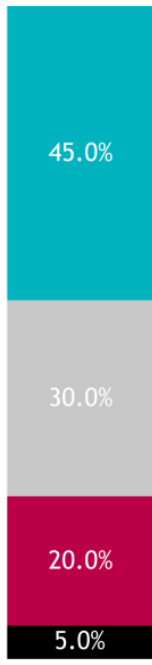

$81.3 \%$

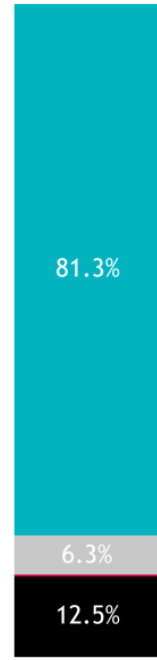

Pre

Some services also benefit clients financially. Evidence gathered by Citizens Advice Sheffield, responsible for delivering Weston Park CSC Welfare Advice service, provides an indication of the financial value of this service to users. Annual reports show that the recorded income gained for clients who were followed up by Citizens Advice amounted to $£ 1,608,004$ for 288 clients in 2016-2017 and £1,375,298 for 233 clients in 2017-18. These figures underestimate the total financial value gained as only a proportion of clients are typically followed up by Citizens Advice each year. People using the service expected the help and advice they received to make a difference particularly to their household income, their ability to cope with financial issues, their quality of life and with employment matters (see Figure 4.2 earlier). However, without more information on how people use the extra money and what difference it has actually made it is not possible to wholly appreciate the impact of this service on people's lives.

The CSC also benefits from essential volunteer support and volunteers also provide information at Weston Park Hospital to cancer patients as outlined in Chapter 1 of this report. Volunteers contribute greatly to the Centre's friendly welcoming atmosphere and helpful service which puts people visiting the Centre at ease, an aspect which is particularly valued:

(I was) Made to feel secure, understood and welcome.

Just having a short time and secure environment to relax has had a hand in feeling more relaxed generally. Thank you!

During 2018 and 2019, 19 Support Centre volunteers contributed 1138 and 1032 hours to the Centre respectively. Fifteen outpatient volunteers contributed just over 250 hours in 2018, and in 2019 two outpatient volunteers undertook 262 hours of volunteering. 
Many projects and organisations find it helpful to put a financial value on the hours their volunteers contribute, and this may be something that Weston Park CSC wants to consider. An assessment of the economic value using UK average weekly wage figures for specific roles (administrative and secretarial and health and social care associate professionals) suggests that volunteers contributed five full time equivalent posts to the Centre at a value of $£ 107,000$ in 2018 and $£ 104,000$ in 2019 . Volunteers also benefit from their role and experience, a survey of Centre volunteers carried out by the Centre in Spring 2018 indicated that:

- all volunteers agreed "my volunteer role gives me a sense of accomplishment."

- 7 in 10 agreed that "my volunteering has helped me develop new job-related skills."

- 9 in 10 agreed that "my volunteering has increased my self-confidence."

Volunteers noted I volunteer because:

(It) gives me great pleasure each time I am at the centre. Staff amazing and all do a fantastic job

I want to give something back to the CSC and the wonderful staff who helped me

I enjoy meeting people, talking to them. My time as a volunteer is a two-way thing- I get so much pleasure from my time here. It has been a great learning curve and very humbling.

There may well be other social benefits emanating from the support provided by the CSC not measured or recognised by the Centre or included in this evaluation. These benefits accrue to beneficiaries of the CSC but also to their friends, families and carers and to wider society. For instance, these could include better-quality family relations and savings in NHS and Social Care services arising from the greater wellbeing and ability to self-manage conditions enjoyed by CSC users or gains in local economic output arising from fewer working days lost. As one attendee of the Bereavement Course put it:

I now feel like returning to work after 7 months. (Bereavement Course.)

\subsection{Summary}

The results presented in this Chapter demonstrate the high level of satisfaction with the CSC services. The Centre provides a warm welcoming and friendly service that helps to put people at ease and makes them feel safe and secure at a time of uncertainty. Services are delivered in a way that is easily understood, and overall the feedback across the courses and services offered is extremely positive. The results outlined above also highlight the considerable social benefits of attending the Centre and the mental wellbeing impacts for those utilising CSC services and courses. However, assessing which courses make the most difference is difficult due to the lack of standardised questions and outcome measures across the services and courses. For instance, utilising national standard health and wellbeing outcome measures would enable comparison between courses and services provided by the Centre and with other similar external initiatives using these measures. Welfare Advice report summaries provide an indication of the financial value of this service to clients, but better follow-up of financial impact would allow the CSC to comprehend the difference this support makes to people's lives. Recording volunteer time and putting a financial value on it shows that volunteers contribute substantial annual economic value to the Centre. 


\section{Recommendations}

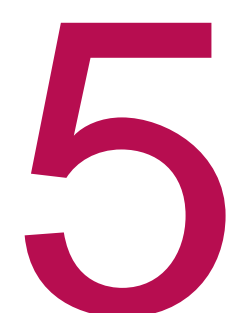

The findings outlined in this report point to recommendations which Weston Park CSC may wish to consider in the future. Weston Park CSC is launching a new strategy in 2019 with a focus on showcasing the work of the CSC in terms of what's been achieved and its future aspirations. The strategy will also set out improvements that are needed to the way the impact of the CSC's charitable investments in different projects is measured and evaluated. The recommendations in this chapter and the key headlines outlined earlier in the report will help inform these aspects of the new strategy.

\subsection{An Important Consideration}

There is evidence of lower use of the CSC from more deprived areas of Sheffield and an underrepresentation of different groups (including men, the over 60s and BAME groups) and types of cancer at the Centre. This pattern of use may partly reflect the current provision of cancer support across Sheffield and ease of access to the CSC, as well as the ability of the Centre to reach out to certain communities. Further investigation is recommended to determine the reasons why certain groups and communities have a lower support up-take at the CSC. The CSC will need to examine and develop new ways of reaching out to these groups in the future. A useful source of information on the uptake of primary and community services in Nottingham of BAME populations with long term conditions and how service providers should engage with these groups effectively can be found here: https://www4.shu.ac.uk/research/cresr/sites/shu.ac.uk/files/primary-communityservices-BAME-people-long-term-conditions.pdf

\subsection{Recommendations for Future Evaluation}

\section{Main database and data collection}

- Weston Park CSC has already made improvements to its main database and recently introduced a unique identifier so that an individual can be identified. This identifier adopted across all services and courses will make it possible to track an individual's use of services more accurately, for example, to see what support an individual is accessing and how many times different services are used.

- $\quad$ Adopting more consistent data entry practices - having a data dictionary to refer to for data entry would help improve data accuracy and aid data analysis. For example, this includes things like consistent formatting of variables and postcodes. Wherever possible a standard set of categories should be applied to each variable. 
- $\quad$ Consider collecting patient NHS numbers. This would potentially allow linking with other health databases and obtaining more accurate demographic and spatial information as well as helping identify which contacts and enquiries were from unique individuals. WP CSC should consult the NHS CCG and NHS Digital around an appropriate form of words for collecting NHS numbers and patient consent for this to be linked to NHS data.

\section{Impact measurement}

This evaluation has detailed some of the considerable benefits for people using the wide range of support services and courses offered by the CSC. In order to improve any future evaluation of the impact of various activities and projects on patients and other users, the Centre should consider the following:

- Adopting standardised outcome measures for general health and subjective wellbeing as part of assessment. Administering a standard health and wellbeing outcomes questionnaire for a robust sample of all patients (and/or for course evaluations) to be completed at induction, certain time intervals and the end of support would establish a general health-related quality of life baseline and measure change for individuals over time. For example, Health related quality of life can be measured using the standardised tool EuroQol five dimensions (EQ5D) questionnaire. This measure is an NHS/NICE recommended tool which enables economic evaluation and the calculation of a Quality Adjusted Life Year (QALY). A QALY is a summary measure of the value of a health outcome, which incorporates the impact on both the quantity and quality of life. Essentially QALYs can be used to compare the benefit and cost of interventions similar to some of the services offered by the CSC. Other measures such as general wellbeing (life satisfaction) link to the Office for National Statistics (ONS) measuring wellbeing programme.

- Other alternative health outcomes measures are also available if more appropriate for the Centre.

- Using a standard set of questions in Course evaluations - there is potential for all course evaluations to include a set of generic questions appropriate to all courses which would make comparative analysis of course information easier. Using standardised outcome measures, as described above, would also help evaluators to assess the relative effectiveness of different courses or combination of courses. If required, more specific questions to a course could also be added after the standard questions, to allow more in-depth information.

- Utilising NHS numbers (as above) would enable the CSC to link with other health databases and follow use of health and social services elsewhere. If health records could be analysed over a period of time it may be possible to assess whether CSC intervention has a bearing on a patient's use of services elsewhere and enable economic analysis of the relative cost of patient's healthcare utilisation over time.

- Valuing volunteer time - Volunteers are integral to the Centre and the support offered to cancer patients. Our calculation shows that volunteer contribute substantial value. The Centre therefore may find it helpful to start putting a financial value on the hours' volunteers contribute. The Centre is now recording volunteering time and contribution and it would be relatively easy to calculate economic value. Volunteer time can be expressed as an annual or monthly figure, or as the number of FTE (full time equivalent) posts. The value of hours that volunteers contribute can be calculated using UK average weekly wage figures or average weekly wage for specific roles. Using a financial calculation to account for volunteers' time is only one way of looking at their value and it will be important for the Centre to think about how to describe or measure a range 
of contributions volunteers bring to the Centre including skills, attributes, ways of working, relationships, networks and so on as well as the effect that undertaking volunteering at the Centre has on the volunteers themselves.

- $\quad$ Gathering in-depth qualitative information and ensuring better follow up of some welfare advice clients. Existing qualitative data collected by the CSC has been employed wherever possible to supplement the evaluation analysis. However, this data is somewhat limited and does not capture the views of all the CSC stakeholders in much detail. Gathering more in-depth qualitative data would help to articulate a range of benefits and impacts of the various services offered by CSC which currently are not being captured. Such data would provide the human interest stories to help showcase the work of the CSC. More detailed follow up on how welfare advice clients have used the extra income gained and what difference this has actually made would help the CSC assess more fully the impact of this service on people's lives. 


\title{
Appendix 1: Methodology and Glossary of Terms
}

\begin{abstract}
Methodology
In total, there were 60,065 recorded contacts with the Cancer Support Centre between January 2014 and March 2019. In order to analyse the frequencies, this database was cleaned and standardised. This involved using a standard term for records where information was missing or unavailable for analysis, in this case the term "not known" was used.
\end{abstract}

35,096 of the total contacts were made by patients. To identify individual patients a full postcode for each contact/enquiry was required, which reduced the sample to 32,821 records when partial, incorrect or unknown postcodes were excluded.

In order to identify which enquiries and contacts were made by individual patients, a number of assumptions were made which involved splitting the sample into distinct groups.

- Firstly, records an individual postcode occurred once, meaning an individual contacted the centre on only one occasion. These are assumed to be one individual person in each case.

- Records matched where the postcode, age group, ethnicity, gender and diagnosis are the same were assumed to be one individual in each case.

- Records where the postcode, ethnicity, gender and diagnosis are the same but the age group is different required additional analysis. The dates of contacts for each postcode were sorted into chronological order. In cases where ethnicity, gender and diagnosis were the same and where the age group was one group older (e.g. 50-59 moving to 60-69) then this was assumed to be the same individual. If the age group is more than one older or was younger, it was assumed this is two or more individuals within one postcode.

- To provide an additional check, the referral method was looked at. Firstly records identifying individual patients using the previous assumptions were sorted chronologically. Each 'individual' patient was then sorted chronologically from their first point of contact.

- The referral type was then looked at and specifically when this occurred amongst all the contacts that each patient has with the centre. The referral types 'multi-disciplinary teams', 'publicity material', 'a friend/relative', 'website', 'media coverage' or 'GP referral', then this referral type should be their first point of contact with the centre.

- If these occurred later in the chronology of contacts, then it is assumed this is actually two or more individual patients who happen to have the same characteristics and postcode. 
- Records that had the same postcode, but characteristics such as ethnicity, age gender, diagnosis etc. differed were assumed to be multiple patients who share a postcode and were categorised as such.

- The original referencing system used by the Cancer Support Centre has been maintained to identify individuals, even if this contradicts the assumptions made as part of this methodology.

- One factor that cannot be taken into consideration, based on the data available to CRESR, is whether individual patients have moved house during the period the records apply to as this would result in a change in postcode.

- It would only be possible to look at this using the full database that included patient names, and even in this instance this would not factor in changes of names (due to marriage etc.) in that time.

- $\quad$ Finally, each individual postcode was geocoded by matching it with the National Statistics Postcode Lookup (NSPL). This identifies the local authority, ward and middle super output area (MSOA) that each patient resides, allowing for further spatial analysis.

\section{Glossary of terms}

- Enquiries and contacts refer to any type of engagement with the Centre.

- Patient enquiries and contacts refer to any type of patient engagement with the Centre.

- The main types of enquiry and contact with the Centre are Drop-in; telephone enquiry/contact and attending a course or service. 


\section{Sheffield Hallam University}

An Evaluation of the Impact of Weston Park Cancer Support Centre

GILBERTSON, Janet <http://orcid.org/0000-0003-3338-7590>, DAYSON, Christopher <http://orcid.org/0000-0003-2402-1183> and LEATHER, David

Available from the Sheffield Hallam University Research Archive (SHURA) at:

http://shura.shu.ac.uk/26227/

\section{Copyright and re-use policy}

Please visit http://shura.shu.ac.uk/26227/ and http://shura.shu.ac.uk/information.html for further details about copyright and re-use permissions. 